\title{
2 Hauptstädtische Monarchie und militärischer Sektor
}

Um die Dynamiken des frühen 7. Jahrhunderts in ihrer Entwicklungslogik nachvollziehen zu können, beginnt diese Untersuchung mit einem eingehenden Blick auf die Strukturmerkmale und Funktionsmechanismen der oströmischen Monarchie in der Spätantike; der Fokus liegt dabei auf zwei Faktoren, die sich in der Analyse als zentral erweisen werden, nämlich auf der Hauptstadt und dem Militär. Die Entwicklung der oströmischen Monarchie des 5. und 6. Jahrhunderts wird von der historischen Forschung in der Regel als Erfolgsgeschichte erzählt. Vor allem im Vergleich zum weströmischen Reich, dessen letzter Kaiser, Romulus Augustulus, im Jahr 476 vom Heermeister Odoaker abgesetzt wurde, erscheint das ungebrochene Fortbestehen römischer Monarchie in Konstantinopel so bemerkenswert wie erklärungsbedürftig. Neben der Betonung kontingenter Faktoren, etwa dem Umstand, dass die militärischen Bedrohungen sich im Osten als weniger gravierend und ressourcenzehrend erwiesen als im Westen, wurden zuletzt auch verstärkt strukturbezogene Erklärungsmuster für die divergierende Entwicklung von ost- und weströmischem Reich angebracht. ${ }^{1}$

Seit Arkadios (395-408) etablierte sich Konstantinopel mit seinen sesshaften und unkriegerischen Kaisern als Zentrum und Fokuspunkt machtpolitischen Geschehens. In der Stadt am Bosporus befand sich nicht nur der kaiserliche Palast; sie beherbergte auch den oströmischen Senat und eines der fünf ökumenischen Patriarchate. Mit der fortschreitenden räumlichen wie ideellen Bindung der oströmischen Kaiser an ihre Hauptstadt ging eine Erweiterung monarchischer Handlungsspielräume und Positionierungsoptionen einher. Während im Westen des Reiches weitgehend unabhängige Feldherren die Hoheit über die Truppen monopolisierten und die Kaiser bisweilen zu bloßen Platzhaltern herabstuften, konnten sich die oströmischen Monarchen von ihrem Sitz in Konstantinopel aus weitestgehend gegenüber dem Militär behaupten. In einem zunehmend christlich geprägten Deutungsrahmen etablierten sich Formen und Verfahren symbolischer Kommunikation, welche die Interaktion zwischen den Kaisern und ihren Untertanen strukturierten. Die Sakralisierung der kaiserlichen Persona und die Liturgisierung von Interaktionsformen ermöglichte es selbst vordergründig schwachen Kandidaten auf dem Thron, ihre monarchische Autorität zu wahren, sich $\mathrm{zu}$ einem gewissen Grad gegen destruktive Einflüsse $\mathrm{zu}$ immunisieren und ihre

\footnotetext{
1 Die Forschung zur oströmischen Monarchie der letzten Jahrzehnte ist enorm vielfältig; die verschiedenen Aspekte werden im Folgenden genauer beleuchtet. Als zentral in der deutschsprachigen Forschung haben sich die Arbeiten von Diefenbach (1996, 2002), Meier (bes. 2012) und Pfeilschifter (2013) erwiesen. Zu den Gründen für das Scheitern der weströmischen Monarchie siehe zusammenfassend Flaig 1997, 23-26; zum weströmischen Reich im Allgemeinen siehe McEvoy 2013 und Börm 2018. Diefenbach 2019, 78-92 hat zuletzt das Verhältnis der Kaiser des 4. und 5. Jahrhunderts zu Rom einer Revision unterzogen.
}

Ә OpenAccess. ( 2021 Nadine Viermann, publiziert von De Gruyter. (c) BY Dieses Werk ist lizenziert unter der Creative Commons Attribution 4.0 International. https://doi.org/10.1515/9783110711356-003 
Herrschaft zu sichern. Ein Kaiser, der eine direkte Verbindung zu Gott beanspruchte und dessen Herrschaft als Mimesis der göttlichen verstanden wurde, konnte nicht zuletzt gegenüber kirchlichen Instanzen eine verhältnismäßig souveräne Position behaupten. Die Position als Vorkämpfer des orthodoxen Glaubens wurde sowohl von den Kaisern betont als auch von der Hauptstadt eingefordert. ${ }^{2}$ Selbst krisenhafte Zustände, wie etwa in der zweiten Hälfte des 5. Jahrhunderts, als auch in Konstantinopel mächtige Heermeister die Kaiser zu überwältigen drohten, konnten anhand des praktischen wie diskursiven Instrumentariums, welches diese hauptstädtische Konfiguration von Monarchie bereitstellte, überwunden und wieder in stabilere Bahnen gelenkt werden. ${ }^{3}$

Der Bedeutungszuwachs Konstantinopels nicht nur als Residenz-, sondern als Hauptstadt zeitigte Auswirkungen darauf, welche Gruppen sich an machtpolitischen Entscheidungsfindungen aktiv beteiligten bzw. sich in derartigen Zusammenhängen als relevant erwiesen: Die Akzeptanz der oströmischen Senatsaristokratie, soweit sie als Funktionselite in Konstantinopel ansässig war, und des hauptstädtischen Volkes kristallisierten sich als maßgeblich heraus; um seine Position zu sichern, musste der Kaiser diese Gruppen mit kommunikativen Mitteln an sich binden. ${ }^{4}$ Das in den Provinzen stationierte Heer dagegen, das noch im 3. und 4. Jahrhundert die Aushandlung monarchischer Herrschaft maßgeblich bestimmt hatte, verlor angesichts der Zentralisierung politischer Entscheidungsprozesse - im Gegensatz zum Westen - zunehmend an Relevanz..$^{5}$ Gemäß Rene Pfeilschifter zeichnete sich das oströmische Reich des 5. und 6. Jahrhunderts durch eine „strukturelle Trennung“ zwischen „drinnen und draußen“ aus. ${ }^{6}$ Monarchische Herrschaft sei während dieser Phase allein im Mikrokosmos Konstantinopel ausgehandelt worden; was außerhalb der Stadtmauern lag, die unter Theodosios II. zu einem kaum bezwingbaren Verteidigungswall ausgebaut worden waren, verlor an Bedeutung: „Das übrige Riesenreich, der ,Rest“, wenn man so will, er gehörte zum politischen System nicht dazu. ${ }^{\text {“7 }}$ Dem Heer erkennt Pfeilschifter folgerichtig die Stellung als Akzeptanzgruppe ab. Während im Westen die Institution des römischen Kaisertums dem Druck einer nichtrömischen Militärelite erlag, ermöglichte die Bindung an Konstantinopel die „Rettung des Kaisertums vor der Dominanz des eigenen Militärs“. ${ }^{8}$

2 Zur Sakralisierung des christlichen Kaisers siehe Martin 1984; Diefenbach 1996, bes. 39; Meier 2003c; Pfeilschifter 2013, 76-85; Leppin 2013; zur Liturgisierung der Interaktionsformen siehe Diefenbach 2002; Meier 2016; ders. 2017, $534 \mathrm{f}$.

3 Zum 5. Jahrhundert siehe Meier 2012, 206-222.

4 Zum Begriff der Akzeptanz und der Akzeptanzgruppe siehe Flaig 1992, bes. 174-207; in Übertragung auf die Spätantike siehe ebd. 1997; Diefenbach 1996, 35; Pfeilschifter 2013, 1-38.

5 Zum Kaiser und der Armee im 3. und 4. Jahrhundert siehe Hebblewhite 2017.

6 Pfeilschifter 2013 und ders. 2014 (Zitat S. 130 und im Titel des Aufsatzes).

7 Zitat Pfeilschifter 2014, 119; zur Stadtmauer als Faktor bei der Abschottung Konstantinopels ebd. 119-130.

8 Zitat Pfeilschifter 2013, 22. Vgl. Martin 1997, 53: „Zwar blieb auch im Osten das Heer eine wichtige Grundlage kaiserlicher Gewalt und spielte die Selbstdarstellung des Kaisers als Sieger weiterhin eine 
Obwohl ich nicht in Frage stelle, dass die Bindung des Kaisers an Konstantinopel entscheidend dazu beitrug, das Überleben der Institution Kaisertum im Osten des Reiches zu sichern, soll im Folgenden die These von der Marginalisierung des militärischen Sektors einer Revision unterzogen werden. Dabei wähle ich eine Perspektive, welche die Zuschreibung von politischer Wirkmächtigkeit nicht allein auf die Unterscheidung zwischen ,Innen“ und ,Außen` zurückführt. Um das Phänomen ,hauptstädtische Monarchie‘ zu ergründen, betont diese Arbeit die konstante Interdependenz von interner und externer Sphäre. Das fortifikatorische Bollwerk im Westen der Stadt mochte zwar zuverlässig vor bewaffneten Eindringlingen schützen, stellte allerdings nicht zwangsläufig ein Hindernis für machtpolitische Impulse dar. Während der hier untersuchten Zeitspanne konnte monarchische Herrschaft allein in Konstantinopel wirksam gemacht werden, wie Pfeilschifter eindrücklich gezeigt hat: Kaiser war derjenige, der die Hauptstadt kontrollierte bzw. von den dort ansässigen Gruppen akzeptiert wurde. Die Faktoren, die machtpolitische Prozesse und damit Möglichkeiten und Grenzen monarchischer Herrschaft bedingten, schlossen allerdings einen wesentlich breiteren Radius bzw. Referenzrahmen ein - nicht nur ideell, sondern auch praktisch. Obwohl die Befestigungsanlagen der Stadt dem Kaiser einen weitreichenden Schutz vor militärischen Übergriffen boten, heißt das nicht, dass es keine Wechselwirkungen zwischen Hauptstadt und Reich, zwischen Kaiser und dem Militär mehr gab.

Die im folgenden dargelegte Perspektive dient dazu, den Blick auf die Remilitarisierung des Kaisertums durch Herakleios im frühen 7. Jahrhundert zu schärfen und in ihrer Entwicklungslogik aufzuarbeiten. Angesichts der Funktion dieses Kapitels für die Arbeit im Ganzen beschränke ich mich darauf, die grundlegenden Charakteristika der Interdependenz zwischen hauptstädtischer Monarchie und militärischem Sektor herauszuarbeiten; eine kleinteilige und quellenbasierte Analyse konkreter Konstellationen kann nur in Ausnahmefällen geleistet werden. ${ }^{9}$

\subsection{Vom Heerführer zum sesshaften Kaiser}

Anders als ihre Vorgänger zogen die oströmischen Kaiser seit Arkadios nicht mehr persönlich in den Krieg. Die Herausbildung einer hauptstädtischen Konfiguration von Monarchie wurzelte also in einem Bruch mit etablierten monarchischen Verhaltensformen. Untersucht man die Interdependenz zwischen hauptstädtischer Monarchie

große Rolle, aber das Kaisertum wurde, vor allem wegen der dauernden Residenz in Konstantinopel, in einen umfassenderen Beziehungszusammenhang eingeordnet.“

9 Außerdem sei darauf hingewiesen, dass im Folgenden auf eine eingehende Untersuchung bzw. Berücksichtigung der Prozesse im Westen des Reiches verzichtet wird. Die Eigenheit der politischen Konfiguration in Konstantinopel, deren Charakteristika oben bereits kurz vorgestellt wurden, erlaubt eine derart einseitige Herangehensweise; einzelne Querverweise auf den Westen werden höchstens genutzt, um die im Osten beobachtbaren Phänomene noch präziser zu charakterisieren. 
und militärischem Sektor, so kommt man kaum umhin zu fragen, warum die oströmischen Kaiser über zwei Jahrhunderte hinweg nicht mehr als Feldherren agierten.

Die Funktion des Kaisers als Imperator, als Oberbefehlshaber der Truppen, war römischer Monarchie von Beginn an inhärent. Bei der Einrichtung des Prinzipats durch Augustus basierte die Autorität des Oberhauptes der römischen Res publica unter anderem in seiner Weisungsgewalt über das Heer. Indem Augustus die republikanische Amts- bzw. Ehrentitulatur, Imperator, als festen Namensbestandteil annahm, monopolisierte er die Möglichkeit militärischen Triumphes für sich und seine Nachfolger. Die Position des Imperator stand dabei in Bezug zu dem Ideal der Propagatio imperii - der Erweiterung der Grenzen des römischen Reiches mit kriegerischen Mitteln. ${ }^{10}$ Nachdem im 1. und 2. Jahrhundert die Intensität der persönlichen Präsenz des Imperators auf den Schlachtfeldern variiert hatte, verschob sich der Fokus kaiserlicher Aktivität ab dem 3. Jahrhundert auf die Sicherung der Reichsgrenzen, die vermehrt externen Bedrohungen ausgesetzt waren. Die Kaiser, die sich nun fast ausnahmslos aus dem Heer rekrutierten, verbrachten einen Großteil ihrer oft kurzen Regierungszeit bei den in den Provinzen stationierten Truppen; das Heer gewann damit als maßgeblicher Faktor für kaiserliche Herrschaft und Herrschaftssicherung gegenüber den vorigen Jahrhunderten noch an Relevanz. Auch das Tetrarchische System und das Residenzkaisertum des 4. Jahrhunderts richteten sich in weiten Teilen nach den Erfordernissen der Grenzsicherung und ermöglichten die Präsenz zumindest eines Augustus bzw. Caesars an den jeweiligen militärstrategischen Brennpunkten. Mit der Regierung des Theodosios I. begann sich das Blatt allerdings zu wenden: Sein Ausbau Konstantinopels als Hauptstadt, die Rom gleichwertig war, stellte die Weichen für die darauffolgenden Jahrhunderte, in denen die Kaiser des oströmischen Reiches persönliche militärische Aktivität einstellten. ${ }^{11}$ Den Titel des Imperators indes behielten auch die sesshaften Kaiser; Sieghaftigkeit blieb integraler Bestandteil kaiserlicher Selbstdarstellung, wurde jedoch von persönlicher kriegerischer Aktivität abgekoppelt und vielmehr als dem Herrscher inhärente Qualität konzipiert. Der unkriegerische Kaiser avancierte zum ewigen Sieger. ${ }^{12}$ Die Soldaten wurden weiterhin auf den Augustus als obersten Dienstherrn eingeschworen - mit dem Unterschied, dass dieser nicht mehr mit ihnen auf dem Schlachtfeld stand, sondern als gotterwählter Herrscher in Konstantinopel für das Wohl seiner Untergebenen betete. ${ }^{13}$

10 Zur militärischen Persona des Augustus siehe Havener 2016.

11 Siehe den Überblick zu „Imperial Involvement in Warfare“ bei Lee 2007, 21-37; zur wachsenden Bedeutung Konstantinopels seit Theodosios I. siehe Maier 2019, 435-441 (architektonischer Ausbau der Stadt), 442-449 (Stabilisierung von Macht); zu der Entwicklung christlich-römischer Monarchie im 4. Jahrhundert siehe auch Leppin 2017.

12 Maier 2019, 451-462 zur Entwicklung vom basileus polemikos zum basileus niketes; Diefenbach 1996, 58; Meier 2009, 260; Pfeilschifter 2016, 4 zur Sieghaftigkeit des sesshaften Kaisers; zur Siegesideologie der hauptstädtischen Monarchie siehe Lee 2007, 37-50.

13 Zum betenden Kaiser siehe Pfeilschifter 2013, 223 und ders. 2014, 140 f. (Beispiel: in Bezug auf den frommen Theodosios II. siehe etwa Sokr. 7.18.15-18). 
Johannes Lydos vermerkte in seiner Schrift De magistratibus, verfasst um die Mitte des 6. Jahrhunderts, dass Theodosios I. seinen Söhnen aufgrund von deren ungeeigneter Kondition per Gesetz verboten habe, persönlich in den Krieg zu ziehen; ${ }^{14}$ auch Arkadios habe in Hinblick auf seinen minderjährigen Sohn Theodosios II. an dieser Regelung festgehalten. Daraus sei ein generelles Gesetz hervorgegangen, welches den römischen Kaisern verbot, in den Krieg zu ziehen, und die Kriegsführung stattdessen den Generälen, den $\sigma \tau \rho \alpha \tau \eta$ oú, übertrug. ${ }^{15}$ In der Forschung herrscht weitgehender Konsens darüber, dass es ein derartiges Gesetz nicht gegeben hat. Bei der Notiz des Johannes handelt es sich wohl vielmehr um den Versuch, eine retrospektiv plausible Erklärung für den Paradigmenwechsel im frühen 5. Jahrhundert zu etablieren - eine Erklärung dafür, dass die römischen Kaiser aufhörten, persönlich in den Krieg zu ziehen, und dass auch diejenigen Kaiser, die - im Gegensatz zu Arkadios und Theodosios II. - angesichts militärischer Erfahrung durchaus als Befehlshaber qualifiziert gewesen wären, nach ihrer Krönung in Konstantinopel blieben. ${ }^{16}$ Die hier umrissene Entwicklung scheint also nicht nur aus Sicht der modernen Geschichtswissenschaft bemerkenswert und erklärungsbedürftig.

Felix K. Maier hat in seiner Habilitationsschrift herausgearbeitet, dass die Konzentration auf Konstantinopel als Haupt- und Residenzstadt bereits mit Theodosios I. eingeleitet wurde, dass der Rückzug seiner Nachfolger also nicht allein mit dem Umstand zu erklären ist, dass anstelle von kriegserfahrenen Männern deren minderjährige Söhne auf dem Thron saßen. ${ }^{17}$ Als Grund für das Sesshaftwerden der ost-

14 Joh. Lyd. De mag. 2.11.

15 Joh. Lyd. De mag. 3.41. Die Passage schildert zunächst, wie Konstantin I. die Prätorianergarden auflöste; die Heereseinheiten wurden unter das Kommando der Comites bzw. Generäle (strategoi) gestellt und die Palastgarden unter die Aufsicht des Magister officiorum: „Und solange es der Fall war, dass die Kaiser persönlich in die Kriege auszogen, hatte das Amt einige Kraft und Macht, und wenn auch nicht so große, dann doch zumindest mehr als die anderen. Von dem Zeitpunkt aber, als es geschah, dass der letzte Theodosius gerade als Kind die Kaiserwürde annahm und er gemäß der Gesetzgebung seines Vaters den Kriegen nicht beiwohnen durfte, und als es durch ein allgemeines Gesetz verhindert wurde, welches dem Kaiser der Römer verbot, in den Krieg zu ziehen, da wurden die Angelegenheiten des Krieges natürlich zum Betätigungsfeld für die Generäle, die Angelegenheiten des

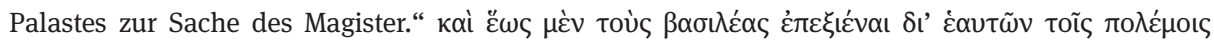

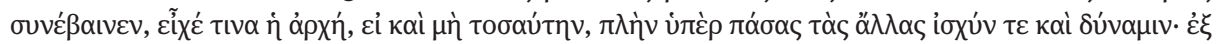

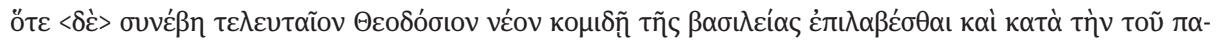
тро̀

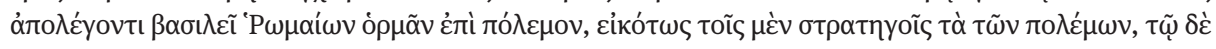

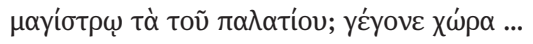

16 Zu Joh. Lyd.vgl. Diefenbach 1996, 41; Szidat 2010, 185; Pfeilschifter 2013, 45 Anm. 11; Maier 2019, 459. Lee 2007, 35 weist darauf hin, dass mit Markian und Leon I. zwar Männer mit militärischer Erfahrung auf den Thron kamen, dass Aspar allerdings ganz bewusst Männer in fortgeschrittenem Alter ausgewählt habe, die ihm in der Truppenführung keine Konkurrenz mehr machen konnten. Erst Zenon brachte dann tatsächlich Potential mit sich, entschied sich aber auch gegen die persönliche Kriegsführung, was gemäß Lee daran gelegen haben könnte, dass die Erinnerung an katastrophale Enden kriegführender Kaiser (Julian, Valens) noch sehr präsent war.

17 Maier 2019, 339-449. 
römischen Kaiser hat Maier eine Konstellation ins Spiel gebracht, die er mit dem Begriff des ,Imperator-Dilemma“ beschreibt: Dem Anspruch an den römischen Kaiser, persönlich als Feldherr und im besten Fall gar als Propagator imperii an den Grenzen des römischen Reiches tätig zu werden, konnten die Monarchen des 3. und 4. Jahrhunderts angesichts der Auswirkungen der Völkerwanderung und eines erstarkenden sassanidischen Reiches nicht mehr gerecht werden. Stattdessen hielt man die Grenzen nur mit Müh und Not; barbarische Stammeseinheiten wurden auf römischen Gebieten angesiedelt und mit Geldzahlungen ruhig gehalten. Usurpationen, die aus dem militärischen Umfeld hervorgingen, brachten den regierenden Kaiser regelmäßig in massive Bedrängnis. Mit dem Rückzug nach Konstantinopel hätten sich die Kaiser, so Maier, dieser Diskrepanz zwischen Erwartung und Wirklichkeit entziehen können; durch die Bindung an die Hauptstadt konnte die monarchische Position unabhängig von kriegerischen Erfolgen eingerichtet werden. ${ }^{18}$ Die Kaiser entzogen sich nicht nur den Risiken der persönlichen Kriegsführung und einer mit Niederlagen einhergehenden Destabilisierung ihrer Herrschaft, sondern erschlossen im hauptstädtischen Umfeld auch alternative monarchische Betätigungsfelder. Während monarchisches Charisma zuvor in hohem Maße von militärischer Performance abhängig gewesen war, verlegten sich die sesshaften Monarchen auf die ostentative Zurschaustellung christlicher Tugenden wie Frömmigkeit und Demut; ihre Person und Position wurde in Konstantinopel sukzessive in einen genuin christlichen Deutungshorizont einschrieben. Mit der Bindung des Kaisers an Konstantinopel ging also eine fortschreitende Sakralisierung des Kaisertums einher, welche die monarchische Position stabilisierte. ${ }^{19}$

Die Herausbildung einer hauptstädtischen Konfiguration von Monarchie brachte neue Handlungsoptionen, aber ebenso Zwänge mit sich. Wie bereits betont, ging mit der Konzentration auf Konstantinopel eine Bedeutungssteigerung des hauptstädtischen Volkes und des Palastumfeldes einher: Um Akzeptanz zu erzeugen und zu verstetigen, musste kaiserliches Verhalten den Bedürfnissen und Erwartungen dieser Gruppen zumindest zu einem gewissen Grad entsprechen. Während in den Jahrhunderten zuvor vor allem das Heer Kaisernähe eingefordert hatte, ${ }^{20}$ war es nun die hauptstädtische Bevölkerung, die auf diese Form der Zuwendung bestehen konnte. Eine neuerliche Abwesenheit und damit einhergehende Vernachlässigung Konstantinopels hätte das Risiko eines Akzeptanzverlustes der maßgeblichen Gruppen mit sich gebracht und die Chancen eines alternativen Kandidaten, die Stimmung der

18 Maier 2019, 1-15 zum Begriff des Imperator-Dilemmas; ebd. 451-462; siehe auch Börm 2016, 625f. $19 \mathrm{Zu}$ diesen neuen Betätigungsfeldern siehe Diefenbach 1996, 2002; ders. 2019, 63-78; Meier 2007; Kelly 2013. Es bleibt zu betonen, dass sich auch diese Akzeptanzbasis und die (christliche) Deutungshoheit der Kaiser mitunter als fragil und kritikanfällig erweisen konnten. Zur Sakralisierung des Kaisertums siehe auch unten S. 198-200.

20 Zum Nahverhältnis zwischen Kaiser und Soldaten im 1. und 2. Jahrhundert siehe Stäcker 2003. 
Hauptstadt auf seine Seite zu ziehen, erhöht. ${ }^{21}$ Die Sicherung Konstantinopels als Dreh- und Angelpunkt monarchischer Herrschaft avancierte zur höchsten Priorität, sodass selbst Männer mit umfassender militärischer Erfahrung nach ihrer Erhebung zum Kaiser die Stadt nicht mehr verließen. Eine Usurpation in der Hauptstadt stellte ein wesentlich größeres Risiko dar als die Rebellion eines Feldherrn in den Provinzen; ${ }^{22}$ die Einnahme Konstantinopels mit militärischen Mitteln war angesichts der enormen Befestigungsanlagen im Westen der Stadt geradezu unmöglich, solange - und darin lag der ausschlaggebende Punkt - die Stadt sich und ihren Kaiser geschlossen verteidigte. Die hauptstädtische Konfiguration von Herrschaft trug zur Sicherung des Kaisertums im Osten des Reiches bei; die Männer auf dem Thron entzogen sich dem - mit Felix K. Maier gesprochen - Imperator-Dilemma, begaben sich damit aber in ein neues Korsett an Verhaltenserwartungen, das ihren Handlungsspielraum in anderer Weise beschränkte.

\subsection{Der sesshafte Kaiser: Auswirkungen auf den militärischen Sektor}

Nachdem die Entwicklungslogik hinter dem Sesshaftwerden der oströmischen Kaiser in ihren Grundzügen beleuchtet wurde, stellt sich nun die Frage, welche Auswirkungen dieser Prozess auf das Verhältnis der Kaiser zum militärischen Sektor zeitigte. ${ }^{23}$ Unter dem ,militärischen Sektor verstehe ich dabei keine eindeutig und unverrückbar definierbare Gruppierung, sondern Bereiche der oströmischen Gesellschaft, die verhältnismäßig klar durch ihre militärische Aktivität geprägt waren. Der militärische Sektor ist sowohl extra als auch intra muros anzusiedeln. Während sich die großen Heeresverbände meist in den Provinzen aufhielten, ist davon auszugehen, dass auch in der näheren Umgebung Konstantinopels Einheiten stationiert waren. ${ }^{24}$

21 Siehe Börm 2013, 81 und ders. 2016, 626f.; Diefenbach 2019, 76 beschreibt die Bindung des Kaisers an Konstantinopel als eine ,janusköpfige Angelegenheit“.

22 Daraus erklärt sich, um ein paar Beispiele zu nennen, dass Zenon nach seiner Rückkehr aus dem isaurischen Exil erst lauthals die persönliche Führung der Kampagne gegen die Goten auf dem Balkan ankündigte (was bei den Soldaten auf Begeisterung stieß), nur um die Entscheidung im letzten Moment zu revidieren und lieber in Konstantinopel seine prekäre Position zu sichern (Malch. fragm. 18.3; vgl. Pfeilschifter 2013, 63), und dass Maurikios’ Entschluss, das römische Heer persönlich gegen die Avaren anzuführen, auf entschiedene Gegenwehr aus Palastkreisen stieß (Theoph. Sim. Hist. 5.16.2-4); dazu unten $74 \mathrm{f}$.

$23 \mathrm{Zu}$ den Auswirkungen des hauptstädtischen Kaisertums auf den militärischen Sektor siehe Lee 2007, 30 -37; Börm 2013, 75-84; ders. 2016, 622, 624-627; Parnell 2017, 98f. Es sei außerdem auf die bisher noch nicht veröffentlichte Dissertation von Anne Poguntke verwiesen, eine Untersuchung zum Amt des Magister militum in der Spätantike (non vidi); siehe vorerst Poguntke 2014 und 2016.

24 Zu den in/bei Konstantinopel stationierten Truppen siehe Pfeilschifter 2013, 225-231; Dagron 1974 , 108 vermutet, dass am Hebdomon einige der vom Magister militum praesentalis befehligten Truppen stationiert waren. 
Innerhalb der Stadt schließlich befanden sich die kaiserlichen Gardesoldaten, die insgesamt mehrere Tausend Mann umfassten. Doch den militärischen Sektor allein mit Verweis auf die Masse der Soldaten zu umreißen, wäre zu kurz gegriffen. Als ebenfalls diesem Sektor zugehörig begreift diese Arbeit Funktionsträger bzw. Befehlshaber, auf höchster Ebene die Magistri militum, die als Mitglieder des Senates das politische Klima der Hauptstadt entscheidend prägten.

\subsubsection{Soldaten}

Bis ins 4. Jahrhundert hatten die römischen Kaiser die direkte Kommunikation mit den Soldaten stets forciert; damit wurden sie der Bedeutung dieser Gruppe für die Stabilität monachischer Herrschaft gerecht: Das Heer - bzw. bestimmte Heereseinheiten rief den Kaiser aus, konnte ihm die Akzeptanz allerdings ebenso wieder entziehen und einen alternativen Kandidaten durch Akklamation zum Kaiser machen; das Heer - bzw. loyale Heereseinheiten - war schließlich auch das einzige Instrument, mithilfe dessen sich ein Kaiser eines potentiellen Konkurrenten erwehren konnte. ${ }^{25}$ Mit dem Rückzug der Kaiser nach Konstantinopel erfuhr das Verhältnis zwischen Kaisern und Soldaten eine maßgebliche Modifizierung. Obwohl auch die hauptstädtischen Kaiser weiterhin durchaus mit Heereseinheiten in Berührung kamen, etwa mit den nahe Konstantinopel stationierten oder regelmäßig durchziehenden Truppen, ${ }^{26}$ zeichnete sich diese Interaktion doch durch eine andere Qualität aus: Der Kaiser führte die Soldaten nicht mehr persönlich in den Krieg; die an den Grenzen stationierten Einheiten bekamen ihn in der Regel gar nicht zu Gesicht. Indirekte Kommunikation fand freilich über Soldzahlungen und Donative statt, die anlässlich spezieller Anlässe ausgezahlt wurden. Das Bildnis und der Name des Kaisers waren weiterhin in den Feldlagern präsent, die Truppen wurden weiterhin auf den Throninhaber eingeschworen. ${ }^{27}$ Zumindest im 5. Jahrhundert zeichneten sich auch Kaisererhebungen noch durch einen militärischen Charakter aus (die Kaiser wurden von anwesenden Truppen auf dem Hebdomon außerhalb der Stadtmauern erhoben); im späten 5. Jahrhundert jedoch wurde das Ritual in den zivilen Raum innerhalb der Stadtmauern verlegt. ${ }^{28}$ Anders als in den Jahrhunderten davor hatte die Erhebung eines

25 Siehe Flaig 1997, $17 \mathrm{f}$.

26 In Folge des Sieges über den Usurpator Eugenios wurde ein Teil der Truppen unter der Führung des Goten Gainas nach Osten zurückgeschickt und von Arkadios vor den Mauern Konstantinopels empfangen. Dass dieses Zusammentreffen überhaupt in den Quellen erwähnt wird, ist dadurch bedingt, dass die Soldaten, die gerade noch Arkadios akklamiert hatten, kurz darauf an gleicher Stelle dessen Praefectus praetorio per Orientem Rufinus ermordeten; zum Rufinus-Attentat und der Quellenlage siehe Poguntke 2016, $253 \mathrm{f}$.

27 Siehe Lee 2007, 51-66.

$28 \mathrm{Zu}$ Erhebungs- bzw. Krönungsritualen siehe vor allem Trampedach 2005; eine ausführliche Diskussion von Krönungsritualen findet sich in Kapitel 3.3.1. 
alternativen Kandidaten durch die Truppen in den Provinzen nun keine direkten Auswirkungen mehr auf die politische Ordnung. ${ }^{29}$ Nur wer Konstantinopel kontrollierte, war römischer Kaiser.

Wie reagierten nun die Soldaten auf diese Entwicklung - die Soldaten, die zuvor stets Kaisernähe eingefordert hatten? Ein schematischer Überblick erweckt den Eindruck, dass im oströmischen Reich die Loyalität der Soldaten auch gegenüber den sesshaften Kaisern aufrechterhalten werden konnte. Während im Westen die Bindung zwischen Heer und Kaiser seit dem späten 4. Jahrhundert zunehmend erodierte und sich mit dem höchsten Heermeisteramt eine Institution etablierte, welche die Hoheit über die Armee dauerhaft sichern konnte, blieben die Soldaten im Osten des Reiches weiterhin direkt auf den Kaiser bezogen. ${ }^{30}$ Meutereien, bei denen ganze Heereseinheiten der Zentrale ihren Gehorsam aufkündigten, sind zwar durchaus zu verzeichnen, entzündeten sich allerdings primär dann, wenn die Soldaten sich in ihrer Versorgung, ihrer Besoldung und ihrem generellen Wohlergehen bedroht sahen. Solange der oströmische Kaiser also die Versorgung der Truppen im Griff hatte und sich ostentativ um das Wohl der Soldaten sorgte, akzeptierten diese das Arrangement eines sesshaften Kaisers und stellten keine genuine Bedrohung für die Stabilität von dessen Herrschaft dar. ${ }^{31}$

\subsubsection{Militärische Funktionsträger}

Komplexer gestaltet sich der Blick auf die zweite Gruppe, auf hohe militärische Funktionsträger. Die Position des Oberbefehlshabers an kriegerischen Brennpunkten, die im 3. und 4. Jahrhundert zumeist von dem regierenden Kaiser bzw. einem Repräsentanten des Kaiserkollegiums ausgefüllt worden war, musste im Zusammenhang mit der Herausbildung der hauptstädtischen Monarchie Kommandoträgern überlassen werden - ein Arrangement, das nicht ohne Konsequenzen bleiben konnte.

29 Mit Blick auf das 5. Jahrhundert wird dies vor allem durch die Erhebung des Leontios in Kilikien deutlich: Obwohl Leontios wichtige Truppeneinheiten hinter sich hatte - unter anderem den isaurischen General Illous - und seine Krönung durch die Witwe des verstorbenen Kaisers Leon I., Verina, unterstützt wurde, zeitigte seine Erhebung keine direkten Auswirkungen auf das politische Klima in Konstantinopel. Zur Usurpation des Leontios siehe Kiel-Freytag 2010 und Pfeilschifter 2013, 557-560. 30 Siehe Flaig 1997, $23 \mathrm{f}$.

31 Siehe Martin 1997, 61; Szidat 2010, 195; Börm 2013, 77. Auch Poguntke 2014, 419-422 betont die Bedeutung einer angemessenen Versorgung für die Loyalität der Soldaten; sei die Versorgung nicht gewährleistet gewesen, habe dies die Position der Feldherren gestärkt (so etwa unter Zenon); ähnlich in Bezug auf das 4. Jahrhundert auch Lee 2015, 103. Lee 2007, 67 weist allerdings darauf hin, dass sich Unruhen von Seiten der Soldaten im 6. Jahrhundert häufen (gegenüber dem 5. Jahrhundert, in dem Unruhen meist von prominenten Individuen ausgingen); zu den Meutereien unter Maurikios siehe unten S. 80 - 82. Zu „military unrest“ ab 471 siehe die Studie von Kaegi 1981; vgl. auch Jones 1964 I, 395 : „The army, somewhat surprisingly, seems very rarely to have made its influence felt.“ 
Potentielle Spannungen zwischen Kaisern und Heermeistern sind ein genuines Charakteristikum römischer Monarchie: In einem politischen System, das nicht auf institutionellen Kriterien beruhte, sondern auf der Generierung und Aufrechterhaltung von Akzeptanz der relevanten Gruppen, stellten erfolgreiche Militärs stets ein Risiko für die Autorität des regierenden Kaisers dar. ${ }^{32}$ Die Entwicklungen des 5. Jahrhunderts indes modifizierten die Parameter, innerhalb derer sich diese Spannungen Bahn brechen konnten. Indem im Kontext der Hauptstadt neue monarchische Betätigungsfelder erschlossen wurden, gelang es den Kaisern, sich zu einem gewissen Grad von den militärischen Funktionsträgern abzuheben, da sie nicht mehr auf dem gleichen Feld (der Kriegsführung) mit diesen konkurrierten. Aus diesem Rückzug in die Hauptstadt erwuchs allerdings ein anderes Dilemma: Um die Sicherung der weiterhin umkämpften Reichsgrenzen zu gewährleisten, waren die sesshaften Kaiser noch stärker von der Leistung und Loyalität ihrer Generäle abhängig und mussten ihnen gleichzeitig relativ große Autonomie in den Provinzen gewähren. Mit der Festigung eines hauptstädtischen Kaisertums gewann der militärische Sektor an Eigenständigkeit. ${ }^{33}$

Das römische Reich fußte, ebenso wie andere vormoderne Imperien, in hohem Maße auf militärischer Schlagkraft. Eine effiziente Verwaltung, welche die steuerliche Ausbeutung der Provinzen zugunsten der politischen Zentrale und somit einen dauerhaften Einkommensfluss ermöglichte, trug ebenfalls zum Prosperieren der Res publica bei; die Machtressourcen und der Grad an Unabhängigkeit, über die hohe militärische Funktionsträger in der Spätantike verfügten, waren allerdings ungleich größer als die ihrer Kollegen aus dem zivilen Sektor. Angesichts des Umstandes, dass die Kaiser sich nicht mehr persönlich als Feldherren betätigten, stellten sie die „Schicht [, auf die der Kaiser] wie auf keine andere angewiesen war.“" ${ }^{34}$ In den Händen der Generäle lag die Sicherung der konstant instabilen Reichsgrenzen und die Beilegung interner Konflikte bis hin zum konkreten Schutz des Kaisers; an ihren Fähigkeiten hing der Erfolg in militärischen Auseinandersetzungen, die weiterhin zu einem gewissen Grad auf den Machthaber in Konstantinopel rückwirkten. Die Stabilisierung oströmischer Herrschaft, welche durch die Bindung an Konstantinopel hatte herbeigeführt werden können, ging also mit dem Umstand einher, dass militärische Funktionsträger in den Provinzen - ungestört von kaiserlicher Präsenz und mit dem

32 Während der ersten Jahrhunderte der Kaiserzeit wurden die hohen Befehlsposten vor allem durch Männer aus dem Ritterstand besetzt, während die Kaiser senatorischen Hintergrund hatten; diese Konstellation ermöglichte einen gewissen Grad an Abgrenzung. Ab dem 3. Jahrhundert wurden dann allerdings vermehrt auch Männer aus dem Ritterstand zum Kaiser erhoben; siehe Lee 2007, 24. 268 wurden Senatoren von den Posten der Legionskommandanten ausgeschlossen, was die Ausbildung einer rein zivilen Karrieresparte bedingte, siehe Szidat 2010, 184.

33 Siehe Demandt 1980, bes. 629 („Die dynastische Legitimation des Kaiserhauses machte principes pueri und principes clausi möglich, doch nur um den Preis, dass jemand anderes die Führung der Truppe in die Hand nahm.“).

34 Demandt 1970, 628. Jones 1964, 174-178 betont dagegen, dass auch die zivilen Funktionsträger im Osten machtpolitisch äußerst bedeutend waren, ähnlich Martin 1997, 53. 
Rückhalt durch die Truppen - entscheidende Machtressourcen akkumulieren konnten. Diese Machtressourcen im provinzialen Rahmen auszuspielen, war angesichts der Fokussierung des politischen Systems auf die Hauptstadt nur in begrenztem Maße möglich: Es erwies sich wiederholt, dass selbst Individuen, die sich bei den Truppen enormen Rückhalt erarbeitet hatten, dem Kaiser in Konstantinopel von der Provinz aus nicht gefährlich werden konnten, solange dieser die Hauptstadt hinter sich hatte. ${ }^{35}$ Doch konnte in den Provinzen gewonnenes militärisches Prestige durchaus auf die machtpolitische Zentrale übertragen werden. Dies musste nicht zwangsläufig durch Usurpation geschehen; ${ }^{36}$ hohen militärischen Funktionsträgern standen neben der direkten und möglicherweise gewaltsamen Herausforderung des regierenden Kaisers subtilere Mittel und Wege zu Verfügung, um den Kaiser in Konstantinopel unter Druck zu setzen und politische Entscheidungsprozesse zu beeinflussen.

Will man die Mechanismen verstehen, die die Interdependenz zwischen dem Kaiser und militärischen Funktionsträgern bedingten, muss zunächst die Zusammensetzung dieser Gruppe genauer bestimmt werden. Dabei geht es nicht darum, die Kommandostruktur des römischen Heeres im Allgemeinen einer Untersuchung zu unterziehen; ${ }^{37}$ der Fokus liegt stattdessen auf der hochrangigen Führungsgruppe, die als Bindeglied zwischen intra und extra muros, zwischen dem militärischen Sektor in den Provinzen und dem politischen Establishment Konstantinopels bis hin zum engeren Palast-Umfeld und dem Kaiser selbst verstanden werden kann.

Um den Blick auf die hohen militärischen Funktionsträger zu schärfen, bedarf es eines Exkurses zu der Zusammensetzung bzw. Formierung der oströmischen Elite in den Jahrhunderten nach der Etablierung des Konstantinopolitaner Senates unter Constantius II. Die politische Elite bestand, kurz gesagt, aus zivilen und militärischen Amtsträgern bzw. ehemaligen Amtsträgern einer gewissen Rangstufe. ${ }^{38}$ Im 4. Jahr-

35 Das beste Beispiel ist Vitalian, der über Jahre hinweg Thrakien kontrollierte, was aber nicht zum Sturz des Kaisers Anastasios führte; zur Revolte des Vitalian siehe Kaegi 1981, 92f.; Meier 2007a, 203209.

$36 \mathrm{Zu}$ Einflussnahmen jenseits der Usurpation siehe Szidat 2010, 213f. („Alternativen zur Usurpation").

37 Zur Kommandostruktur siehe etwa Jones 1964 II, 654-656 und Mi. Whitby 2000b, 288-290.

38 Der Begriff der ,Elite‘, ebenso wie ,Adel` und ,Aristokratie‘, wird in der Forschung zur Spätantike nicht unbedingt einheitlich angewandt. Börm 2010, 146 weist darauf hin, dass es sich dabei trotz der Existenz zeitgenössischer Termini um moderne Konstrukte handelt. Die Kriterien hinsichtlich der Zugehörigkeit zu einer bzw. der Elite schwanken in der Literatur: „Abstammung, eine Position in einer offiziellen - herrscherlichen oder religiösen - Hierarchie, Grundbesitz, Nähe zum Herrscher, die Anerkennung durch die peers (wohl der wichtigste Punkt) sowie ein entsprechender Lebensstil“ (Börm 2010, 164). Pfeilschifter 2013, 452 dagegen zählt zur Elite diejenigen, „die mit dem Kaiser wenigstens gelegentlich als Individuen in Kontakt treten konnten“; einen umfassenden Überblick über die Forschung zu und Definition der oströmischen Elite findet sich bei Begass 2018, 6-14; vgl. auch Whately 2013, 50 und Meier 2008 mit einem Überblick über „Aristokratie(n) in Byzanz“. Die von Begass gewählte Herangehensweise (explizit ebd. 12f.), als Elite erst einmal diejenigen zu fassen, die durch die Belegung bestimmter Ämter der Rangklasse der Illustres zuzuordnen sind, halte ich für sinnvoll. Dass dadurch kirchliche Würdenträger ausgeschlossen werden, lässt sich bei der hier vorzunehmenden 
hundert war im Osten gemäß dem Cursus honorum die Bekleidung einer Praetur Voraussetzung für den Übergang vom provinzialen Curialen- in den Senatorenstand. Unter Theodosios I. kam es zu einer Erweiterung der Zugangsmöglichkeiten, was einen geradezu inflationären Zuwachs derjenigen Männer zur Folge hatte, die zumindest nominell dem Konstantinopolitaner Senat angehörten. Mit Markian setzte eine Gegenbewegung ein, welche die höchste senatorische Rangklasse der Illustres gegenüber denen der Spectabiles und Clarissimi bevorzugte: Allein die Illustres stellten nun den aktiven Senat in Konstantinopel, während die Spectabiles und Clarissimi verstärkt an ihre Heimatstädte in den Provinzen gebunden wurden. Unter Justinian erfolgte schließlich eine weitere Binnendifferenzierung der Illustres, die eine noch deutlicher begrenzte Führungsschicht eng mit dem Kaiser verknüpfte. Die Zugehörigkeit zur Rangstufe der Illustres war nicht erblich (Söhne von Illustres hielten als solche nur den Rang des Clarissimus), sondern an die Bekleidung bestimmter ziviler und militärischer Ämter gebunden. Der Kaiser konnte Ämter auch ehrenhalber verleihen und bestimmte Individuen durch die Verleihung des Patrikiats als höchste Würde, die sich mit keinerlei Aufgaben verband und auf Lebenszeit verliehen wurde, innerhalb der Riege der Illustres privilegieren. ${ }^{39}$ Diese Konskriptionspraxis brachte eine vergleichsweise hohe vertikale Mobilität mit sich: Durch die Besetzung illustrer Ämter als Alternative zum traditionellen Cursus honorum stiegen im 5. und 6. Jahrhundert vermehrt Männer nicht-distinguierter Herkunft in illustren Rang auf und bildeten in Konstantinopel ein Gegengewicht zu den Erben aristokratischer Familien. ${ }^{40}$

Die oströmische Elite, wie sie sich im Laufe des 5. Jahrhunderts herauszubilden begann, unterschied sich demnach stark von der stadtrömischen. Bereits A. H. M. Jones formulierte prägnant: „The new hierarchy effectively transformed the aristocracy from one of birth into one of office." 41 Der Senat in seiner ursprünglichen Funktion als Beratungs- und Entscheidungsgremium verlor zunehmend an institutioneller Bedeutung; die Konzentration auf illustre Amtsträger führte allerdings zu einem Erstarken des Einflusses seiner Mitglieder, die sich als politische Führungsschicht, als Amts- bzw. Funktionselite, in Konstantinopel um den Kaiser sammelten

Untersuchung verkraften; vgl. Av. Cameron 2004 mit dem Versuch einer Typologisierung der Elite: neben der politischen, d.h. der Senatsaristokratie, identifiziert sie auch eine kirchliche und intellektuelle Elite.

$39 \mathrm{Zu}$ den Illustres siehe die prosopographische Studie von Begass 2018, die alle Männer dieses Ranges zwischen 457 und 518 n.Chr. auflistet; zum Rang des Illustris ebd. 42-45 und zu den Spectabiles und Clarissimi ebd. 52-54. Zu ehrenhalber verliehenen Ämtern siehe ebd., 54f.; zum Patrikiat ebd., 45f., 419f. Im Westen trug nur der Magister utiusque militiae den Titel des Patricius, was die umfassenden Vollmachten dieser Position verdeutlicht. Im Osten dagegen wurde das Patrikiat stets mehreren Männern verliehen, die eine Gruppe enger kaiserlicher Amicii bzw. Berater konstituierten. 40 Zu der Entwicklung des Senates siehe zuletzt im Überblick Begass 2021 und ders. 2018, bes. 35- 41 und 480 - 485; Olster 1993, 26 -35; Jones 1964 II, 528f.; außerdem mehr mit Blick auf die Entwicklung im 6. - 8. Jahrhundert Haldon 1990, 166 -172, 389-399; ders. 2004.

41 Jones 1964 II, 529; siehe auch Begass 2018, 44. 
und als Comitatus, als dessen engster Beraterkreis, fungierte. ${ }^{42}$ Während eine ganze Reihe ziviler Ämter einen illustren Rang mit sich brachte (der Comes domesticorum, der Magister officiorum, die Praefecti praetorio, der Praefectus urbi, der Praepositus sacri cubiculi, um nur einige zu nennen), wurde auf dem militärische Karrierepfad nur den Magistri militum diese Auszeichnung gewährt. ${ }^{43}$ Fragt man nach dem Einfluss des militärischen Sektors auf machtpolitische Prozesse in Konstantinopel, erweist sich also die Untersuchung der aktiven und ehemaligen Magistri militum als vielversprechend, die sich - nicht selten von verhältnismäßig niedriger Herkunft - bis in eines dieser Oberkommandos hochgearbeitet hatten und damit zu Mitgliedern der hauptstädtischen Polit-Elite avancierten.

Die Gruppe illustrer Militärs lässt sich für die Spätantike verhältnismäßig gut umreißen. In der Kaiserzeit waren zivile und militärische Kompetenzen in den Händen der Statthalter, der senatorischen Legati Augusti pro praetore, vereint gewesen. Mit dem Ausschluss der Senatoren vom Militärdienst durch Gallienus wurde allerdings der Grundstein für die Herausbildung zweier eigenständiger Karrierewege gelegt, die unter Diocletian und Konstantin noch klarere Form annahmen: Die Notitia dignitatum unterscheidet schließlich klar zwischen einer zivilen und einer militärischen Verwaltungsebene. ${ }^{44}$ Wie klar diese beiden Ebenen im 5. und 6. Jahrhundert im praktischen Vollzug voneinander getrennt waren, bleibt in der Forschung umstritten. Während Alexander Demandt gar die Herausbildung eines „Militäradels“ postuliert, der sich sowohl im west- als auch im oströmischen Reich über mehrere Generationen hinweg gefestigt habe, ${ }^{45}$ wird von anderer Seite betont, dass bisweilen durchaus personelle Überschneidungen zwischen ziviler und militärischer Verwaltung bestanden; ${ }^{46}$ zum Ende des 6 . Jahrhunderts begannen sich beide Bereiche dann tatsächlich wieder stärker miteinander zu verschränken, nicht zuletzt in Form der neu eingerichteten Exarchate in Karthago und Ravenna. ${ }^{47}$ Doch selbst wenn nicht von einer kategorischen Trennung zwischen militärischer und ziviler Administration auszuge-

42 Börm 2010, 169f. (mit weiteren Literaturverweisen): „Als Institution besaß der spätantike Senat kaum noch Einfluss, sehr wohl aber als Versammlung der Reichsaristokratie. Er bündelte gewissermaßen die auctoritas seiner Mitglieder.“

43 Eine Übersicht über Ämter und Titel mit illustrem Rang findet sich bei Begass 2018, 60 f.; vgl. auch ebd. 420, wo darauf verwiesen wird, dass Zugang zum Senat über militärische Ämter gegenüber den zivilen stark beschränkt war - als Grund dafür nimmt Begass an, dass die oströmischen Kaiser aus den Entwicklungen im Westen, d.h. der dortigen Dominanz hoher Militärs, gelernt hätten. Laut Demandt 2007, 307 hatte auch der Comes domesticorum illustren Rang.

44 Demandt 2007, 292; Szidat 2010, 184. Dabei bleibt zu betonen, dass sowohl die militärischen als auch die zivilen Funktionsträger als Militia bezeichnet wurden, die Militia armata bzw. Militia officialis; vgl. Kelly 2004, 20.

45 Demandt 1980: Militäradel als distinkte Gruppe an militärischen Funktionsträgern, die sich nicht/ kaum mit der etablierten Aristokratie verband; vgl. bereits Demandt 1970, 785. In Reaktion auf Demandt siehe Gluschanin 1991; vgl. Begass 2018, 8. Zur Herausbildung und Bedeutung einer Militär-Elite im 4. Jahrhundert siehe auch Frank 1969, 167-199.

46 So etwa Olster 1993, $34 \mathrm{f}$.

$47 \mathrm{Zu}$ den Exarchaten siehe Meier 1998. 
hen ist, lässt es sich rechtfertigen, Männer, die als Magister militum dienten bzw. gedient hatten, als eine distinkte Gruppe innerhalb der hauptstädtischen Elite zu behandeln. ${ }^{48}$

Wie lässt sich nun diese Gruppe illustrer Militärs genauer charakterisieren? Die militärische Kommandostruktur des oströmischen Reiches unterschied sich wesentlich von der im Westen: Während im Westen der Magister utriusque militiae als Befehlshaber des gesamten Feldheeres über eine umfassende Machtvollkommenheit verfügte - auf Kosten der oft unmündigen Kaiser -, wurde das Amt des Magister militum im Osten auf mehrere Kommandos aufgeteilt. Nach der Rückkehr des Heeres, das im Westen den Usurpator Eugenius bekämpft hatte, schuf Theodosius I. fünf gleichrangige Kommandos mit eigenen Truppenkontingenten - neben zwei Magistri militum praesentales jeweils einen per Orientem, Illyricum und Thraciam. ${ }^{49}$ Unter Justinian kamen noch weitere Kommandos dazu, per Italiam et Africam, per Armeniam und Spaniae..$^{50}$ Gezielte Maßnahmen der oströmischen Kaiser bzw. hoher Palastkreise, zivile Ämter zu begünstigen und die Verfügungsgewalt militärischer Funktionsträger in Schranken zu halten, zeigten - so die gängige Forschungsmeinung - die erhoffte Wirkung. ${ }^{51}$ Limitierte Reichweite, interne Konkurrenz, eine zeitliche Befristung, ständige Rotation und häufige Wechsel der Kommandos - oft wurden sie nur für ein Jahr besetzt - führten dazu, dass die Heermeister des Ostens zu keinem Zeitpunkt die Machtressourcen akkumulieren konnten, über die ihr Counterpart im Westen verfügte. ${ }^{52}$ Das Schicksal der weströmischen Kaiser, die sich seit dem Aufstieg des Stilicho der dauerhaften Bevormundung und gar Überwältigung durch ihre Magistri utriusque militiae ausgesetzt sahen, konnte im Osten abgewandt wer-

48 Siehe Börm 2013, 75 Anm. 59: „Die militia armata war von der militia officialis (und der militia palatina) klar unterschieden. Es gab nun kaum noch Männer, die durch ihre Laufbahn mit beiden Sektoren verbunden waren, und die Machtbalance zwischen den beiden Bereichen war empfindlich.“ Vgl. auch Meier 2008, 294, der in seiner Übersicht zur byzantinischen Aristokratie auf die „partiell zutreffende und in ihren Konsequenzen viel zu wenig untersuchte Differenzierung zwischen dem ,Zivil-“ und dem ,Militäradel“" hinweist.

49 Jones 1964 I, 343 f. Zum Magister utriusque militiae im Westen siehe Enßlin 1931; O’Flynn 1983; Castritius 1984; McEvoy 2013 zu den Dynamiken zwischen minderjährigen Kaisers und mächtigen Heerführern.

50 Jones 1964 II, 655 f. Zum Amt des Magister militum und seiner Entwicklung in Ost und West sei auf die nach wie vor einschlägige Untersuchung von Demandt 1970 verwiesen; außerdem zusammenfassend ders. 2007, 311-313.

51 Begass 2018, 420; Demandt 1970, 784.

52 Lee 2007, 33f. und ders. 2015, 104, 112; zur Vergabepraxis von Ämtern im Allgemeinen siehe Begass 2018, 415-429; zu befristeter Besetzung von Ämtern ebd., 417-419; zur Befristung militärischer Kommandos unter Justinian siehe Parnell 2017, 83f. und ders. 2012, 7-9. Siehe auch Börm 2016, 622 Anm. 82, der darauf hinweist, dass die Aufteilung des Kommandos der Perseroffensive des Jahres 503 auf fünf Generäle militärstrategisch kontraproduktiv war, allerdings dadurch zu erklären ist, dass Anastasios einen potentiellen Persersieg nicht einem einzigen Mann überlassen wollte. 
den. ${ }^{53}$ Spätestens nachdem die Krise überwunden worden war, die das politische Klima Konstantinopels in der zweiten Hälfte des 5. Jahrhunderts destabilisierte, ${ }^{54}$ hätten die oströmische Kaiser - so gemeinhin die Ansicht der Forschung - relativ frei sowohl über die zivilen als auch über die militärischen Amtsträger, versammelt in der hauptstädtischen Senatsaristokratie, verfügen können. ${ }^{55}$

Eine derartige Lesart basiert allerdings auf der Grundannahme eines recht einseitigen Verhältnisses zwischen Kaiser und Angehörigen der Eliten, die in der Literatur bisweilen anklingt. Der Kaiser als alleiniger Fokus eines fest etablierten Patronagesystems wird dabei - überspitzt gesagt - einer abhängigen Funktionselite ohne eigenständige Gruppenidentität gegenübergestellt: Ämtervergabe und Besetzungsentscheidungen lagen - so offenbar die Einschätzung - im Ermessen des Kaisers; er war es, der über den Aufstieg in die höchsten gesellschaftlichen Schichten entschied. In der Macht des Monarchen habe es gestanden, „die Hierarchie der höfischen Gesellschaft beständig umzuformen und diese ihre Abhängigkeit deutlich fühlen zu lassen“. ${ }^{56}$ Die Senatoren werden als eine ohnmächtige Elite, als loyales Gefolge gezeichnet, die sich um Kaisernähe als das höchst-gehandelte Gut bemühten. ${ }^{57}$ Anstatt sich als Mitglieder einer homogenen und distinguierten Führungsgruppe zu begreifen, hätten sich die höchsten Würdenträger allein in ihrer Stellung und Beziehung zum Kaiser definiert und profiliert. ${ }^{58}$,Je loyaler sie [i.e. die Angehörigen der Elite] ihm [i.e. dem Kaiser] dienten, desto mehr Verantwortung, Macht und Prestige konnten sie erwarten. " ${ }^{\circ 9}$ Wettstreit bzw. Konkurrenz habe primär auf der Ebene der Peers stattgefunden; dem übermächtigen Kaiser habe man kaum etwas entgegenzusetzen gehabt. $^{60}$

53 Der Gothe Gainas scheint versucht zu haben, in Konstantinopel eine dem Stilicho ähnliche Stellung zu okkupieren, scheiterte allerdings unter anderem an dem Widerstand der hauptstädtischen Bevölkerung; siehe Börm 2013, 76 und ausführlicher Faber 2011.

$54 \mathrm{Zu}$ dieser Krise siehe Meier 2012, 206-222.

55 Dazu Börm 2013, 79: Das „Primat des kaiserlichen Hofes und des ,zivilen“ Sektors“ habe sich erneut durchgesetzt.

56 Zitat Pfeilschifter 2012, 141; zur Ernennungspraxis von militärischen Funktionsträgern verschiedener Rangstufen siehe Parnell 2017, 79-83.

57 Betonung der Loyalität zum Kaiser als ausschlaggebendes Kriterium für eine lange und erfolgreiche Karriere auch bei Begass 2018, 421, ähnlich Begass 2021; vgl. auch Parnell 2017, $100 \mathrm{f}$.

58 Zur „Ohnmacht der spätantiken Hofeliten“ siehe Pfeilschifter 2012, passim (bes. 145), zur „Vereinzelung der Eliten“ ebd. 140; ebenfalls zu den oströmischen Eliten ders. 2013, 452-465. Siehe auch Begass 2018, 424: „die politische Architektur mit dem Kaiser als Zentrum und den Senatoren als Trabanten [führte] zu einem permanenten Kampf um Aufmerksamkeit, Privilegien - kurz: um Kaisernähe (...).“ Vgl. zum späten 6. Jahrhundert Olster 1993, 35: „The Constantinopolitan aristocracy by the end of the sixth century was far from a politically, socially or culturally cohesive elite. Rather, it was a dependent client of imperial patronage, whose weakness stemmed from its dependence on civil or military offices to maintain itself.“

59 Zitat Pfeilschifter 2012, 140.

$60 \mathrm{Zu}$ innersenatorischer Konkurrenz und wie sie vom Kaiser ausgenutzt wurde siehe Begass 2018, $424-429$. 
Diese Lesart hat in Grundzügen durchaus ihre Berechtigung: Die oströmischen Kaiser konnten sich - im Gegensatz zu den Augusti im Westen - als unumstrittener Bezugspunkt des politischen Systems halten. Den Schlüssel zum Aufstieg in der hauptstädtischen Funktionselite primär in der Loyalität zum Kaiser zu vermuten, wird jedoch meiner Ansicht nach den komplexen Prozessen und Dynamiken der hauptstädtischen Monarchie des 5. und 6. Jahrhunderts nicht ganz gerecht. Die Position des Kaisers als Gravitationspunkt des Konstantinopolitaner Beziehungsgeflechts war zweifelsohne gesetzt; seine Souveränität in Hinblick auf politische Entscheidungsprozesse - wie etwa die Besetzung hochrangiger Ämter - war allerdings eingeschränkt. Obwohl sich Loyalität gegenüber dem Kaiser durchaus auszahlen konnte und dieser offensichtlich darum bemüht war, ein abhängiges Gefolge um sich zu scharen, gehen Angehörige der Eliten keineswegs in einer Charakterisierung als loyale Untertanen auf; vielmehr standen ihnen - zumindest manchen von ihnen - Mittel und Wege zur Verfügung, den Kaiser unter Druck zu setzen und Entscheidungsfindungen zu ihren Gunsten zu beeinflussen. Der Kaiser war mit einer Gruppe hochrangiger Individuen konfrontiert, die versuchten, anhand ihrer jeweiligen Ressourcen machtpolitische Interessen durchzusetzen.

Ihr Engagement an den Kriegsschauplätzen und die Verfügungsgewalt über ihre Truppen ermöglichte es militärischen Funktionsträgern, sich eine eigenständige Auctoritas aufzubauen, die sich als soziales Prestige auch in die Hauptstadt übertragen ließ. Hatten sie die Stellung des Magister militum erreicht, wurden selbst Männer von niedriger Herkunft in die Konstantinopolitaner Elite aufgenommen und drangen damit von der Provinz in die Sphären vor, innerhalb derer monarchische Herrschaft ausgehandelt wurde. Die Kaiser ihrerseits bewegten sich auf dem schmalen Grat zwischen der Notwendigkeit einerseits, von Generälen erfochtene Erfolge anzuerkennen, und der Wahrung kaiserlicher Autorität und Überlegenheit andererseits: Leistung auf dem Schlachtfeld musste zu einem gewissen Grad gewürdigt werden, um die fähigen Männer angemessen zu entlohnen und ihre Loyalität zu sichern; ${ }^{61}$ je deutlicher erfolgreiche Militärs allerdings in Konstantinopel exponiert wurden, als desto bedrohlicher erwiesen sie sich im Ringen um die Aufrechterhaltung der hauptstädtischen Hierarchie.

Ein Triumph im engeren Sinne stand erfolgreichen Feldherren freilich nicht mehr zu; seit Augustus blieb diese Ehre dem Princeps vorbehalten. Auch der Vandalentriumph des Jahres 534, welcher in der Literatur entlang der Terminologie Prokops lange Zeit als „Triumph des Belisar“ bezeichnet wurde, muss - wie zuletzt in der Forschung wiederholt betont - vielmehr als Machtdemonstration Justinians verstanden werden. ${ }^{62}$ In dem wechselvollen Verhältnis zwischen Justinian und Belisar offenbart

61 Siehe Lee 2007, 68f. und ders. 2015, $109 \mathrm{f}$.

62 MacCormack 1986, 125-129; Meier 2002, 287f.; ders. 2003a, 150-165; ders. 2019b. Börm 2013 plädiert für eine explizite Demütigung des Belisar durch Justinian während der Feierlichkeiten; vgl. dazu Pfeilschifter 2017, 459-461, der in Anm. 9 die Thesen Börms relativiert. Zum Triumph von 534 siehe auch Diefenbach 2019, 92-100, der betont (96f.), dass siegreiche Feldherren im 5. und 6. Jahr- 
sich exemplarisch das Dilemma, in dem sich die Kaiser bezüglich hoher militärischer Funktionsträger befanden: Trotz wiederholter Verdachtsmomente hinsichtlich der Loyalität des Generals war Justinian auf die offenbar außergewöhnlichen Fähigkeiten Belisars angewiesen; auf öffentliche Erniedrigungen und unehrenhafte Entlassungen folgte stets die Rehabilitation. ${ }^{63}$

Ein häufig eingeräumtes Zugeständnis an verdiente Generäle bestand in der Verleihung des Konsulates, des höchsten säkularen Amtes, welches in der Spätantike seine ursprüngliche politische Funktion eingebüßt hatte und primär repräsentativ ausgerichtet war. Der Konsulat ging mit einer verstärkten Präsenz im öffentlichen Raum Konstantinopels einher: Die jeweiligen Inhaber waren zur Ausrichtung prächtiger Pompae aus eigenem Vermögen verpflichtet und konnten durch die Euergesia, die sie dabei zur Schau stellten, wiederum bei der hauptstädtischen Bevölkerung als wichtiger Akzeptanzgruppe Prestige aufbauen. Auch dem Belisar wurde im Jahr nach seinem Vandalensieg der Konsulat verliehen, anlässlich dessen er prunkvolle Spiele ausrichtete. ${ }^{64}$ Dabei ist $\mathrm{zu}$ betonen, dass der Konsulat keinesfalls militärischen Funktionsträgern vorbehalten war; auch zivile Beamte und verstärkt Verwandte des regierenden Kaisers bekleideten das Amt. ${ }^{65}$ Dass Justinian die Besetzung des Konsulates 541/2 einstellte, ist vor dem Hintergrund zu verstehen, dass der jeweilige Kandidat dem Kaiser durch seine öffentliche Exposition gefährlich in die Quere kommen konnte; als Justinians Neffe und Nachfolger Justin II. den Konsulat wiederbelebte, war und blieb dieses Amt ein Privileg des Kaisers bzw. der kaiserlichen Familie. ${ }^{66}$

Die Rivalität zwischen Kaisern und militärischen Funktionsträgern im hauptstädtischen Raum wurde durch den Umstand verschärft, dass letztere seit der Wende vom 4. zum 5. Jahrhundert wieder verstärkt private bewaffnete Einheiten um sich zu scharen begannen, die in der Forschung in der Regel unter dem Begriff ,Bukellarier“

hundert den Siegesfeierlichkeiten in der Hauptstadt in der Regel fernblieben; zu kaiserlicher Triumphalpraxis siehe unten 197f., 254-256.

63 Zu der von Belisar ausgehenden Bedrohung siehe Börm 2010, 177 f.; ders. 2013, 86 Anm. 127; ähnlich Meier 2002, 284f. Nach der Eroberung Karthagos 533 soll sich Belisar auf dem Thron des Gelimer

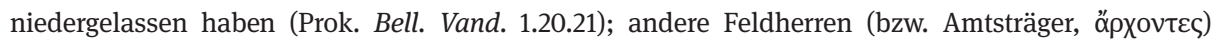
schwärzten den noch in Africa weilenden Belisar bei Justinian an, indem sie ihm vorwarfen, eine Usurpation anzustreben (Prok. Bell. Vand. 2.8.1-5). Im Zusammenhang mit der Belagerung Ravennas wurde Belisar von den Goten das weströmische Kaisertum angetragen; Belisar nahm das Angebot allerdings nur zum Schein an, um Ravenna einzunehmen; siehe Prok. Bell. Goth. 6.29.17-41; dazu Jones 1964 I, 278; Börm 2008, 152.

64 Diefenbach 2019, 95.

65 Jones 1964 II, $532 \mathrm{f}$.

66 Zum Konsulat siehe Begass 2018, 47-49, der auch festhält: „Die Kaiser mussten in den Consuln eine permanente mögliche Bedrohung ihrer eigenen Macht sehen.“ Zum Ende des Konsulates siehe Meier 2002, der zwar auch die potentielle Rivalität zwischen Kaiser und Konsuln betont (bes. 282), allerdings zu dem Schluss kommt, dass es angesichts der massiven reichsweiten Umbrüche um 540 für die altrömische Institution des Konsulates keinen Raum mehr gegeben habe (298). Zum spätantiken Konsulat im Allgemeinen siehe Sguaitamatti 2012, bes. 108-125 zur Ernennungspraxis. 
zusammengefasst werden. ${ }^{67}$ Während des Prinzipats war eine derartige Praxis streng reglementiert gewesen, um die Hoheit des Kaisers über militärische Einheiten nicht zu gefährden. Doch als die Kaiser sich ab dem späten 4. Jahrhundert von den Kriegsschauplätzen in ihre Residenzen zurückzogen und der direkte Bezug zwischen Monarch und Herr vor allem im Westen zu erodieren begann, begegnen uns wiederholt bewaffnete Hausmächte, die sowohl west- wie auch oströmischen Amtsträgern unabhängig von dem jeweils besetzten Kommando direkt unterstellt waren; Demandt spricht gar von einer „Privatisierung des Heeres“. ${ }^{68}$ Belisar soll laut Prokop aus eigener Tasche 7000 Reiter beschäftigt haben. ${ }^{69}$ Die Quellen legen nahe, dass Generäle ihre bewaffneten Gefolgschaften, die vor allem als Leibwache gedient zu haben scheinen, keineswegs vor den Mauern Konstantinopels entließen; vielmehr standen diese ihnen auch innerhalb der Stadt zur Verfügung und konnten im Konfliktfall die Interessen des Dienstherren auch gegenüber dem Kaiser verteidigen, bzw. dies zumindest versuchen: Nachdem der Kaiser Leon I. den Magister militum praesentalis Aspar im den kaiserlichen Gemächern hatte ermorden lassen, rannten dessen $\mathrm{Bu}$ kellarier gegen den Palast an und konnten nur durch die kaiserlichen Gardesoldaten zurückgehalten werden. ${ }^{70}$ Unter Justinian scheint es zu einer graduellen Einhegung dieses Phänomens gekommen zu sein - zumindest insofern, als dass derartige Gefolgschaften in kriegerischen Konflikten regelmäßig auch zugunsten des Kaisers eingesetzt wurden: Laut Prokop führte Belisar zusätzlich zu den römischen Truppen Einheiten seiner Bukellarier in den Krieg gegen die Vandalen. ${ }^{71}$ Die grundlegende Problematik war damit jedoch keinesfalls gebannt. Dass die Bukellarier auch im frühen 7. Jahrhundert noch innerhalb Konstantinopels machtpolitisch relevant waren, zeigt das Beispiel des Magister militum und Comes excubitorum Priskos, der seine Bukellarier 610 in seinem Anwesen zusammenzog, als sich in der Stadt Widerstand gegen den noch regierenden Kaiser Phokas regte. ${ }^{72}$ Als es Herakleios nach seiner Erhebung zum Kaiser gelang, den widerspenstigen Priskos zu entmachten, gliederte er dessen Bukellarier umgehend in seine eigenen Einheiten ein. ${ }^{73}$ Dass Amtsträger über bewaffnete Einheiten verfügten, die primär an sie anstatt an den Kaiser gebunden waren, kann als Epiphänomen der Entwicklung betrachtet werden, dass die Hoheit der Monarchen über den militärischen Sektor in der Spätantike zunehmend brüchig

$67 \mathrm{Zu}$ den Bukellariern siehe zuletzt Wijnendaele (im Druck).

68 Demandt 1980, 632.

69 Prok. Bell. Goth. 3.1.20. Unabhängig davon, ob man der konkreten Zahl Glauben schenkt oder nicht, zeigt der Abschnitt, über welche Mittel hohe militärische Funktionsträger mitunter verfügten.

$70 \mathrm{Zu}$ Aspar Malalas 14.40; auch Markian scharte bei seinem Usurpationsversuch gegen Zenon eine Riege von ihm untergebenen Soldaten um sich; siehe Joh. Ant. fragm. 303; Theoph Conf. AM 5971 (De Boor 126).

71 Prok. Bell. Vand.1.11.1-21; siehe Jones 1964 I, 273; Koehn 2018, 174 zu der Expeditionsarmee. Zu der Entwicklung der Bukellarier im 6. Jahrhundert siehe Wijnendaele (im Druck).

72 Joh. Ant. fragm. 321.

73 Nik. Brev. 2; die Dynamiken zwischen Priskos und Phokas bzw. Priskos und Herakleios werden unten 99f., 153-156 ausführlich diskutiert. 
wurde; diese Konstellation konnte wiederum zu einer Zuspitzung der Konflikte zwischen Kaiser und hohen militärischen Funktionsträgern führen. Die Versuche der Kaiser, die Privattruppen ihrer Amtsträger mit gesetzlichen Mitteln einzuschränken, erwiesen sich langfristig als erfolglos. ${ }^{74}$

\subsubsection{Kaiserliche Garden}

Wie bereits ihre Vorgänger verfügten auch die sesshaften Kaiser in Konstantinopel über ein Corps an Elitesoldaten, das ihnen als Leibwache diente. Gegenüber dem Feldheer waren die Gardesoldaten angesichts ihres engen Verhältnisses zum Kaiser privilegiert. In den Quellen finden sie zahlreiche Erwähnung: Sie treten sowohl in zeremoniellen Zusammenhängen auf (etwa bei der Erhebung von Kaisern) als auch bei städtischen Unruhen, wo sie in der Regel ihrer eigentlichen Funktion nachkommen, nämlich dem Schutz des Palastes und des Kaisers. Bisweilen wurden die Gardesoldaten auch zur Verteidigung der Stadt eingesetzt. ${ }^{75}$

Die Entwicklung der kaiserlichen Garden lässt sich folgendermaßen zusammenfassen: ${ }^{76}$ Im Nachklang seines Sieges über Maxentius löste Konstantin die Prätorianergarde auf und entkleidete den Prätorianerpräfekt, dessen Machtvollkommenheit ein dauerhaftes Risiko für den Kaiser darstellte, seiner militärischen Kompetenzen. Anstelle der Prätorianer übernahmen die Scholae palatinae den Schutz des Kaisers. Mit der Niederlassung der Kaiser in Konstantinopel ging der Wandel der Scholae von einer mobilen Einsatztruppe, die mit dem Kaiser durch das Reich reiste, zu einer dauerhaft in der Hauptstadt ansässigen Institution einher. Die Notitia dignitatum nennt sieben Einheiten der Scholae, die in und um Konstantinopel stationiert waren. ${ }^{77}$ Als Leibwache im engeren Sinne zeichnete sich die Gruppe der Candidati durch besondere Nähe zum Kaiser aus. ${ }^{78}$ Der Dienst in einer der Gardeeinheiten war höchst

$74 \mathrm{Zu}$ den Bukellariern siehe Schmitt 1994; Demandt 2007, 312f., Szidat 2010, 202f. und zu dem Versuch, Bukellarier gesetzlich zu verbieten, siehe Börm 2010, 168; Wijnendaele (im Druck) zu „legal and social status“ der Bukellarier.

75 Siehe Pfeilschifter 2013, 239-245; vgl. Croke 2005b, 146.

76 Die in Konstantinopel stationierten Gardesoldaten waren keine homogene Gruppe, sondern einer Reihe verschiedener Einheiten zugeordnet, deren Zusammensetzung, Organisation, spezifische Funktion und Verhältnis zueinander der Forschung nach wie vor Rätsel aufgibt.

77 Not. dign. or. 11. Mit einer Stärke von ca. 400 Mann pro Einheit ist von einer Gesamtzahl um 2800 Männer im 5. Jahrhunderte auszugehen. Unter Justinian wurde ihre Zahl auf 3500 aufgestockt (Prok. Hist. arc. 24.15).

78 Die Protectores bzw. Protectores domestici stellten eine weitere Gruppe von Gardesoldaten mit spezifischem Zuständigkeitsbereich dar, aus der zumindest im 4. Jahrhundert noch hohe Offiziere rekrutiert wurden. Umfassend zu den Scholae palatinae Frank 1969; außerdem Jones 1964 II, 613 f; Dagron 1984, 113-115; zu den Protectores siehe Jones 1964 II, 636-640; Frank 1969, 179-168 und Haldon 1984, 130 - 136. 
begehrt und brachte soziale wie finanzielle Privilegien mit sich. ${ }^{79}$ In dem Zusammenhang dieser Arbeit ist entscheidend zu betonen, dass die Scholae nicht zum Zuständigkeitsbereich der Heermeister gehörten - selbst die beiden Magistri militum praesentales hatte keinen Zugriff auf sie; stattdessen waren sie administrativ einem Zivilbeamten, dem Magister officiorum, untergeordnet. ${ }^{80}$ Unter Leon I. trat neben die Scholae eine weitere, 300 Mann starke Einheit, die Exkubitoren, mit einem Comes an der Spitze, welche als besonders schlagkräftiges Elitecorps für den Schutz der Ein- und Ausgänge des kaiserlichen Palastes zuständig waren. ${ }^{81}$ Mit der Schaffung der Exkubitoren, die übers 6. und 7. Jahrhundert hinweg ihre Stellung als wichtigste Gardeeinheit sicherten, ging ein Bedeutungsschwund der Scholarier einher, zumindest in Bezug auf ihre militärische Schlagkraft. Sie blieben als Einheit bestehen, fungierten allerdings primär in zeremoniellen Kontexten als Schautruppe, deren prestigereiche Mitgliedschaft als Ehrerweisung verliehen bzw. mit Geld erkauft werden konnte. ${ }^{82}$ Die Befehlshaber der Garden können wiederum als distinkte Gruppe innerhalb der militärischen Funktionsträger ausgemacht werden. Obwohl die Einheiten, über welche die verschiedenen Gardekommandeure im 5. und 6. Jahrhundert verfügten, zahlenmäßig kleiner waren als die, die früher etwa ein Prätorianerpräfekt befehligt hatte, darf ihre Stellung nicht unterschätzt werden: Je enger die Bindung des Kaisers an Konstantinopel, desto größer die Bedeutung der Garden bzw. die Vollmacht ihrer Kommandeure im Verhältnis zum Kaiser. ${ }^{83}$

79 Frank 1969, 174-179.

80 Die effektive Befehlsgewalt unterlag allerdings - so Haldon 1984, 142-150 - offenbar dem Comes domesticorum. Die sieben Einheiten der Scholae wurden jeweils von einem Tribun befehligt. Vgl. Croke 2005a, 163-175 zu Zenon als Comes domesticorum und seinem Verfügungsbereich.

81 Zu den Exkubitoren siehe Jones 1964 II, 658 - 659; Frank 1969, 206 - 213; Haldon 1984, 136 - 141; Ma. Whitby 1987, 483-488; Pfeilschifter 2013, 241f. In der Forschung herrschte lange die Ansicht, dass Leon I. die isaurisch dominierten Exkubitoren als Gegengewicht zu den Scholae geschaffen habe, deren größtenteils germanische Mitglieder zu diesem Zeitpunkt unter dem Einfluss des alanischen Heermeisters Aspar gestanden hätten; siehe Frank 1969, 203-205. Diese Ansicht wurde zuletzt zwar mit dem Verweis darauf relativiert, dass es bereits vor Leon I. eine gleichnamige Einheit gegeben habe; so Croke 2005b und 2005a, 169-171, der sich auch gegen die klare Dichotomie Scholae = germanische Garden und Exkubitoren = isaurische Garden ausspricht. Es ist jedoch kaum zu leugnen, dass die Exkubitoren, ob zuvor bereits als Einheit in Konstantinopel existent oder nicht, durch Leon I. eine klare Bedeutungssteigerung erfuhren. Ich halte es weiterhin für gerechtfertigt, hinter dieser Maßnahme den Versuch Leons zu sehen, seine Position in der Hauptstadt durch eine an ihn persönlich gebundene und schlagkräftige Truppe zu sichern und potentieller Fremdbestimmung vorzubeugen; siehe Börm 2013, 78. Börm 2010, 168 weist darauf hin, dass es kaum ein Zufall gewesen sein wird, dass ausgerechnet Leon I. als „Gründer der neuen Garde“ Privatleuten gesetzlich verbot, sich mit Bewaffneten zu umgeben (Cod. Iust. 9.12.10).

82 Zu den Scholae im 6. Jahrhundert siehe Jones 1964 II, 657 f.; Frank 1969, 213 - 217; Haldon 1984, 119 128, bes. 125-128; zu den Candidati, die im kaiserlichen Zeremoniell auch im 6. Jahrhundert weiterhin eine Rolle spielten, siehe Ma. Whitby 1987, 464-466.

83 Sowohl der Magister officiorum als auch der Comes domesticorum und Comes excubitorum gehörten als Illustres der politischen Elite der Hauptstadt an. 
Die Palastgarden waren nie strikt von den außerstädtischen Militäreinheiten getrennt; es gab sowohl Überschneidungen als auch wechselseitigen Einfluss. Gardesoldaten wurden aus dem Heer rekrutiert, ehemalige Gardesoldaten fungierten als Magistri militum, Gardisten bzw. deren Befehlshaber konnten vom Kaiser für militärische bzw. diplomatische Missionen in die Provinzen gesandt werden und ab dem Ende des 6. Jahrhunderts wurden Comites excubitorum auch verstärkt als Heermeister eingesetzt. Die direkte Interaktion mit und Befehlsgewalt über die Garden, die gegenüber den einfachen Soldaten eindeutig privilegiert wurden, bot den Kaisern nicht nur die Möglichkeit, eine derart schlagkräftige Truppe stärker an die eigene Person zu binden, als es bei den Provinzheeren der Fall war; indem sie vertraute Gardisten in die Provinz zum Heer abordneten, konnten auch die sesshaften Kaiser eine gewisse, wenn auch nicht persönliche Kontrolle über den militärischen Sektor in den Provinzen erreichen und ein Gegengewicht zu der Machtposition der Generäle etablieren. ${ }^{84}$

Innerhalb des hier behandelten Zeitraumes scheint die Loyalität der Garden gegenüber ihrem Kaiser grundsätzlich gefestigt gewesen zu sein. In prekären Situationen standen sie ihm entschieden zur Seite. ${ }^{85}$ Eine Revolte gegen den regierenden Kaiser, die von den Reihen der Garden ausging, ist im 5. und 6. Jahrhundert nicht zu verzeichnen. Erst wenn ein Kaiser massiv an Gunst eingebüßt hatte und das Fortbestehen seiner Herrschaft geradezu aussichtslos erschien, kam es zu Abfällen. Als der Anastasius-Neffe Hypatios während des Nika-Aufstand gegen Justinian im Hippodrom zum Kaiser akklamiert wurde, weigerten die kaiserlichen Garden sich, zugunsten des Justinian in das Geschehen einzugreifen; die gewaltsame Niederschlagung des Aufstandes konnte nur durch Feldeinheiten gelingen, kommandiert von den Befehlshabern Belisar und Mundos. ${ }^{86}$ 610, als die Flotte des Usurpators Herakleios vor Konstantinopels ankerte und Phokas in der Stadt zunehmend an Rückhalt verlor, stellten sich die Exkubitoren unter ihrem Kommandanten Priskos geschlossen gegen den noch regierenden Kaiser. ${ }^{87}$

Zwischenfazit: In der Forschung wurde wiederholt betont, die Bindung der oströmischen Monarchen an ihre Hauptstadt habe einerseits die individuelle Herrschaft gesichert und andererseits das Überleben der Institution Kaisertum ermöglicht, während ihre westlichen Kollegen am Druck einer übermächtigen Militärelite zu Grunde gingen. Allerdings darf dabei nicht übersehen werden, dass sich auch die oströmischen Kaiser hoher militärischer Funktionsträger erwehren mussten. Wie oben

84 Siehe Dagron 1974, 113-115; zu Entsendungen von Gardesoldaten (bzw. gar Comites excubitorum) in die Provinz siehe Jones 1964 II, 658 f. und Pfeilschifter 2013, 243 Anm. 78; zur Rekrutierungspraxis im oströmischen Reich ab 400 (römisch- vs. barbarisch-stämmige Mitglieder) siehe den Überblick bei Frank 1969, 201-219, außerdem Pfeilschifter 2013, 245.

85 Nach der Ermordung Aspars durch Leon I. schützten die Exkubitoren den Palast vor dessen Bukellariern (Malalas 14.40).

86 Prok. Bell. Pers. 1.24.39-51.

87 Joh. Ant. fragm. 321; Chron. Pasch. AD 610; zum Sturz des Phokas siehe ausführlich unten Kap. 3.2; zur Frage der Loyalität der Garden vgl. Pfeilschifter 2013, 245 f. 
nachvollzogen, verlor die Masse des Heeres für die Aushandlung monarchischer Herrschaft tatsächlich an Relevanz, nachdem die Kaiser sich in Konstantinopel niedergelassen hatten; auch die städtischen Garden scheinen keine genuine Bedrohung für die sesshaften Monarchen dargestellt zu haben. Hohe militärische Funktionsträger indes konnten trotz der administrativen Strukturen, die ihren Einfluss beschränkten, erhebliche Machtmittel akkumulieren. Zunehmend selbstbewusste und unabhängige Militärs, teilweise mit nichtrömischem Hintergrund, die entweder offiziell in Amt und Würden und somit als Teil der hauptstädtischen Eliten agierten oder als Warlords vom Balkan aus die Hauptstadt bedrohten, schränkten die Handlungsmöglichkeiten der oströmischen Kaiser ein. ${ }^{88}$ Diese Entwicklung bündelte sich in der Person des alanischen Heermeisters Aspar, der als Magister militum praesentalis maßgeblichen Einfluss auf die Erhebung der Kaiser Markian und Leon I. nahm und von Letzterem nur unter Mühen aus dem Weg geräumt werden konnte. Leons Emanzipation gegenüber seinem ehemaligen Gönner war allerdings teuer erkauft: Sie gelang, indem er mit dem Isaurier Zenon einen konkurrierenden Heermeister und dessen Clique aufbaute; 474 trat Zenon dann als Leons Schwiegersohn auch dessen Nachfolge an. ${ }^{89}$ Strukturelle Unsicherheiten hinsichtlich der Besetzung des Kaiserthrones - etwa die Frage, welche sozialen, ethnischen bzw. religiösen Gruppen überhaupt dafür in Frage kamen führten in der zweiten Hälfte des 5. Jahrhunderts zu andauernden Machtkämpfen und machten das Kaisertum in den Worten Mischa Meiers „disponibel“. Die Entwicklung im Westen, wo sich gezeigt hatte, dass Herrschaft über die Römer auch ohne römischen Kaiser funktionieren konnte, mag als Exempel gedient und die Prozesse im Osten beeinflusst haben. ${ }^{90}$

Eine entscheidende Wende sieht die Forschung in der Regel in der Erhebung des Anastasios 491, der im Gegensatz zu seinen Vorgängern vor seiner Krönung als Palastbeamter, als Silentiarios, gedient hatte. Anastasios' Sieg über die aufständischen Isaurier unter Zenons Bruder Longinos, der als General selbst Ambitionen auf den Thron gezeigt hatte, gilt als Emanzipation einer zivil-urbanen Sphäre gegenüber der Bevormundung durch hohe Militärs. Darüber hinaus zeitigte unter Anastasios ein Sakralisierungsschub nicht nur stabilisierende Wirkung auf dessen Position im hauptstädtischen Kontext, sondern auch auf die Institution des Kaisertums im Ganzen. Spätestens hinsichtlich der Herrschaft Justinians kann Henning Börm konstatieren, dass sich „der Vorrang von Herrscher und Hof gegenüber der militia armata wieder fest etabliert [hatte]““.91

88 Meier 2012, 215.

89 Bei Croke 2005a wird diese Konstellation ausgiebig untersucht. Dass Zenon es als erster Magister militum selbst bis auf den Thon geschafft habe, habe laut Meier $(2012,217)$ einen Präzedenzfall geschaffen und Nachahmer angespornt - das erkläre die verhältnismäßig häufigen Usurpationsversuche während Zenons Regierungszeit.

90 Siehe Meier 2012, 206 -222, Zitat 218. Zu den Auswirkungen des Endes weströmischer Monarchie auf die oströmische Herrschaftskonfiguration vgl. ders. 2014c.

91 Zu Anastasios Meier 2009; Meier 2012, 119-222; Börm 2013, 79, 86 (Zitat). 
Ohne eine Stabilisierung der oströmischen Monarchie in der ersten Hälfte des 6. Jahrhunderts leugnen zu wollen, meine ich doch, dass eine derartige Sichtweise zu einem gewissen Grad den Kern des hier behandelten Problems verdeckt: Die Rivalität zwischen einem sesshaften Kaiser und hohen militärischen Funktionsträgern war kein individuelles Phänomen, welches sich auf bestimmte Personenkonstellationen reduzieren lässt, sondern ein strukturelles, wie im folgenden Unterkapitel genauer erläutern werden soll. ${ }^{92}$ Weder der Sieg des Anastasios über die Isaurier noch die unter Justinian auf neue Ebenen gehobene Sakralisierung konnten die Bedrohung des sesshaften Kaisers durch den militärischen Sektor grundsätzlich aus dem Weg räumen; zumindest in latenter Form musste der Machthaber in Konstantinopel sich mit dieser stets auseinandersetzen.

\subsection{Mechanismen politischer Entscheidungsprozesse}

Im Folgenden soll die These von der Bedrohung der sesshaften Kaiser in Konstantinopel durch den militärischen Sektor untermauert werden. Ein Überblick über die Mechanismen politischer Entscheidungsprozesse und die dabei tonangebenden Akteure wird zeigen, in welchem Maße hohe militärische Funktionsträger die Autorität der sesshaften Kaiser des 5. und 6. Jahrhunderts beeinträchtigen konnten. Geht man davon aus, dass das Ziel militärischer Funktionsträger ein Zuwachs an Macht, Status, Einfluss und damit auch Vermögen war, konnte dieses Ziel - zumindest im oströmischen Reich - nachhaltig nur in Bezug zum Kaiser erreicht werden, der die politischen Prozesse zumindest nominell steuerte und sanktionierte. Das heißt, militärische Funktionsträger konnten entweder versuchen, den regierenden Kaiser unter Druck zu setzen, um bestehende Kommandos zu verstetigen bzw. neue Kommandos zu erwirken und damit ihre Machtbasis zu erweitern, oder sie konnten ihre Reichweite und ihr Prestige nutzen, um die Besetzung des Thrones direkt $\mathrm{zu}$ beeinflussen. Letzterer Punkt - die Besetzung des Thrones - dient als roter Faden des nun folgenden Überblickes.

Die Frage nach den Mechanismen monarchischer Sukzession in der Spätantike ist eine oft gestellte; zuletzt hat Henning Börm die maßgeblichen Tendenzen zusammengefasst. Im Zuge der Reichskrise des 3. Jahrhunderts entschied vorrangig militärische Schlagkraft über die Besetzung des Thrones. Das Prinzip, nach welchem dem bzw. den (militärisch) fähigsten Kandidaten die Lenkung der Res publica übertragen wurde, prägte auch die Ausgestaltung der diokletianischen Tetrarchie. Nicht Blutsverwandtschaft, die während des Prinzipats eine zunehmend wichtige, wenn auch nicht alleinig ausschlaggebende Rolle gespielt hatte, sondern individuelle Eignung und Verdienst bestimmten über die Zusammenstellung des Herrscherkollegiums: je zwei Augusti und Caesares, die durch Heiratsallianzen miteinander verbunden waren.

92 Darauf, dass es sich um ein strukturelles Problem handelt, verweist auch Börm 2010, $166 \mathrm{f}$. 
Mit Konstantin, der sich entgegen der Konzeption des tetrarchischen Systems als leiblicher Sohn des verstorbenen Augustus Constantius Chlorus erst als Caesar und schließlich als Augustus durchsetzen konnte, erfolgte ein erneuter Aufschwung des dynastischen Prinzips. Seinen Bruch mit dem tetrarchischen System versuchte Konstantin - letztendlich erfolgreich - durch die Betonung von consanguinitas als maßgeblichem Kriterium für monarchische Sukzession zu kompensieren. Die von Konstantin gesetzten Maßstäbe stellten die Weichen für die weitere Entwicklung: Bis in die Mitte des 5. Jahrhunderts entstammten alle reichsweit anerkannten Kaiser (mit Ausnahme Jovians) erst der konstantinischen und später der valentinianisch-theodosianischen Dynastie. Dabei bleibt mit Henning Börm zu betonen, dass die spätantike Monarchie zu keinem Zeitpunkt die Form einer institutionalisierten Erbmonarchie annahm: Monarchische Sukzession war und blieb weiterhin grundsätzlich verhandelbar. Dynastische Verbindungen wogen schwer, wurden allerdings durch eine Reihe weiterer, potentiell ausschlaggebender Faktoren ausbalanciert. ${ }^{93}$

Das Ziel dieses Kapitels ist es herauszuarbeiten, welche Rolle der militärische Sektor bei der Nachfolgeregelung im oströmischen Reich des 5. und 6. Jahrhunderts spielte bzw. welche Impulse von diesem ausgingen. Dabei geht es hier weder um die eigentlichen Kaisererhebungen, welche die zuvor gefällte Entscheidung für einen bestimmten Kandidaten performativ umsetzten und wirksam machten, ${ }^{94}$ noch um die zeitgenössischen Deutungen von Selektionsprozessen bzw. getroffenen Wahlen, wie sie uns in den Quellen entgegentreten. Stattdessen sollen die Mechanismen hinter der Entscheidungsfindung aufgedeckt werden; konkret gesagt steht die Frage im Vordergrund, welche Personen als Thronfolger aufgebaut wurden, wer nach dem Tod eines Kaisers tatsächlich zum Zuge kam $^{95}$ und wer den Kaiser durch bisweilen offene Usurpation herauszufordern versuchte. Ich werde dafür argumentieren, dass monarchische Sukzession, solange sie nicht strikt entlang des dynastischen Prinzips verlief und Herrschaft vom Vater an den Sohn übertragen werden konnte, primär von den Interessen hoher militärischer Funktionsträger bestimmt wurde, bisweilen gehemmt durch das Bemühen einer zivilen/urbanen Sphäre, sich im Ringen um Macht und Einfluss zu behaupten.

Die Praxis, leibliche Söhne noch zu Lebzeiten zum Nachfolger zu designieren, die sich bereits während des Prinzipats etabliert und mit Konstantin erneut verfestigt hatte, fand auch im oströmischen Reich des Spätantike Anwendung. Theodosios I. übertrug die Herrschaft an seine Söhne Arkadios und Honorius. Der in Konstantinopel residierende Arkadios krönte 402 seinen Sohn Theodosios II. im Alter von nur einem

93 Siehe Börm 2015a; außerdem Szidat 2010, 165-182 und Lee 2007, 27 f.; zum oströmischen Reich im Speziellen siehe auch Diefenbach 1996, 37f.; zu monarchischer Sukzession außerdem Dagron 2003, 13-53 und Omissi 2018, 3-12.

$94 \mathrm{Zu}$ Krönungsritualen siehe Trampedach 2005; die Funktion derartiger Inszenierungen wird unten Kap. 3.3.1 im Detail besprochen.

$95 \mathrm{Zu}$ den Voraussetzungen für eine Erhebung zum Kaiser in der Spätantike (Untersuchungszeitraum 337-467) siehe Szidat 2010, 182-187. 
Jahr zum Augustus. ${ }^{96}$ Nach Arkadios konnte eine derartige Form der dynastischen Sukzession indes nicht weitergeführt werden: Bis ins späte 6. Jahrhundert bekamen die oströmischen Kaiser keine Söhne mehr. ${ }^{97}$ Allein bei Basiliskos, der den Kaiser Zenon 475 kurzzeitig vom Thron verdrängen konnte, lag die Herrschaftsübergabe vom Vater an den Sohn zumindest in der Luft: Er erhob seinen Sohn Markos erst zum Caesar und kurz darauf zum Augustus. Bei der Rückkehr Zenons im Jahr 476 wurden allerdings beide Männer abgesetzt. ${ }^{98}$ Angesichts des Nichtvorhandenseins leiblicher Söhne erfolgte bisweilen die Designation männlicher Blutsverwandter zweiten Grades: Leon I. (457-474) erhob seinen Enkel Leon II., den Sohn seiner Tochter Ariadne, zum Augustus; dieser verstarb jedoch bereits kurz nach dem Tod seines Großvaters. ${ }^{99}$ Justin I. (518-527) krönte seinen Neffen Justinian kurz vor seinem Tod zum Augustus. ${ }^{100}$ Männliche Blutsverwandte des Kaisers konnten aber durchaus auch übergangen werden; sowohl Anastasios als auch Justinian, die beide mehrere Neffen hatten, verstarben, ohne einen Nachfolger designiert zu haben. Erst Maurikios (581-602) hatte gleich mehrere Söhne; seinen Ältesten, Theodosios, erhob er im Alter von sieben Jahren zum Augustus. ${ }^{101}$ Maurikios' Bemühungen, eine neue Dynastie zu etablieren, fanden allerdings beim Staatsstreich des Jahres 602, bei dem der Kaiser mitsamt seiner männlichen Nachkommen ermordet wurde, ein abruptes Ende.

Als beim überraschenden Tod des Theodosios II. 450 kein männlicher, dynastisch legitimierter Nachfolger zur Verfügung stand, erwies sich die Initiative des alanischen Magister militum praesentalis Aspar als ausschlaggebend. ${ }^{102}$ Als Sohn des Ardabur, der sich bereits in die höchste militärische Riege des Reiches hochgearbeitet hatte, begann Aspar seine Karriere unter Theodosios II., bekleidete als Magister militum mehrere Kommandos und im Jahr 434 gar den Konsulat. Seine Stellung in der politischen Elite Konstantinopels war derart gefestigt, dass er mit Markian, seinem ehemaligen Domestikos, und Leon I., dem Tribun der in Selymbria stationierten Truppen, 450 bzw. 457 zwei Männer aus seinem Umfeld auf den Thron bringen konnte, während er selbst weiterhin das Amt des Magister militum praesentalis besetzte. ${ }^{103}$ Um die

96 Chron. Pasch. AD 402; siehe Diefenbach 1996, 38 auch zur Bedeutung der weiblichen Mitglieder des Kaiserhauses bei der Sukzession.

97 Verina, die Frau des Leon I., brachte einen Sohn zur Welt, der allerdings früh starb; siehe Croke $2005 a, 158$.

98 Zur Usurpation des Basiliskos und Zenons Rückkehr siehe Pfeilschifter 2013, 536 - 544; zu Markus siehe PLRE II, Marcus 4 (720).

99 PLRE II, Leo 7 (664f.).

100 Siehe Croke 2007, 43-55.

101 Die Umstände der Erhebung des Theodosios werden unten 72f. diskutiert.

$102 \mathrm{Zu}$ Aspar und seiner Einflussnahme siehe Trampedach 2005, 285; Pfeilschifter 2013, 512-535; zu den Entscheidungsträgern nach Theodosios' Tod siehe auch Szidat 2010, 397-400. Einen Überblick über die ereignisgeschichtlichen Zusammenhänge von der Erhebung des Marcian bis zur Regierung des Anastasios bietet Jones 1964 I, 217-237.

103 PLRE II, Fl. Ardabur Aspar (164-169); siehe auch Jones 1964 I, 181 f. und zum Hintergrund und Aufstieg des Aspar siehe Croke 2005a, 149-163. 
Erhebung des Markian, der über keine eigenständige Reputation verfügte, mit der nötigen Legitimität $\mathrm{zu}$ versehen, wurde dieser mit Pulcheria, der jungfräulichen Schwester des verstorbenen Theodosios II., in einer Jakobs-Ehe verheiratet. ${ }^{104}$ Ohne selbst je nach dem Purpur zu greifen, ${ }^{105}$ baute Aspar seine Machtfülle bzw. die seiner Familie stetig aus: Sein Sohn Patrikios heiratete 470 Leons Tochter Leontia und wurde zum Caesar erhoben, was einer Designation gleichkam. ${ }^{106}$ Doch Leon ließ sich die Bevormundung durch seinen ehemaligen Gönner auf die Dauer nicht gefallen: In der Person des isaurischen Militärs Zenon baute er einen alternativen Kandidaten auf. Bereits 466/67 hatte Leon diesen mit seiner älteren Tochter Ariadne verheiratet und sukzessive zum Comes domesticorum und Magister militum erhoben. Als Aspar auf Befehl Leons hin 471 im Palast ermordet wurde, deckte Zenon seinem Schwiegervater den Rücken. ${ }^{107}$ Den Rang des Augustus erreichte Zenon allerdings erst 474 nach dem Tod des Leon I., als ihn dessen kurzzeitiger Nachfolger, Zenons Sohn Leon II., im Hippodrom krönte. ${ }^{108}$

Zenons Regierung (474-491) war durch anhaltende Unruhen geprägt. ${ }^{109}$ Kurz nach dem Tod seines Sohnes Leon, der ihn als alleinigen Augustus zurückließ, gelang dem Basiliskos die einzig zumindest zeitweilig erfolgreiche Usurpation im oströmischen Reich des 5. und 6. Jahrhunderts. Diesen Coup als „Palastverschwörung“ zu bezeichnen, wie es etwa Henning Börm tut, ${ }^{110}$ ist meiner Ansicht nach zu einseitig. Zwar nahm Basiliskos, der Bruder der Augusta Verina und somit Schwager des verstorbenen Leon I., als ehemaliger Konsul, Patrikios und Caput senatus durchaus eine herausgehobene Stellung innerhalb der hauptstädtischen Elite und des kaiserlichen Palastes ein; seine Position hatte er sich allerdings auf einer militärischen Laufbahn erarbeitet: Nach verschiedenen Kommandos in den Provinzen besetzte er zuletzt das Amt des Magister militum praesentalis. Auch die Männer, die Basiliskos’ Vorhaben unterstützten, zeichneten sich durch militärischen Hintergrund aus. ${ }^{111}$ Nach Zenons Flucht aus der Hauptstadt übernahm die Augusta Verina die Krönung ihres Bruders

104 PLRE II, Marcianus 8 (714f.).

105 Siehe Meier 2012, $206 \mathrm{f}$.

106 PLRE II, Iulius Patricius 15 (842f.); ein weiteres Indiz, dass es bei Patrikios tatsächlich um die Nachfolge ging, war, dass er vom arianischen Glauben zum orthodoxen, d.h. zum Chalkedonense konvertierte; vgl. Demandt 1970, 757.

107 Die Dynamiken des Machtkampfes zwischen Leon I. und Aspar werden detailliert bei Croke 2005a aufgeschlüsselt; zum Aufbau Zenos ebd. 163-175.

108 PLRE II, Fl. Zenon 7 (1200).

109 Zu Zenon siehe die Monographie von Kosinski 2010; außerdem Meier 2012, 215-222; Pfeilschifter 2013, 536-561.

110 Börm 2013, 78 Anm. 82.

$111 \mathrm{Zu}$ nennen wären prominent Armatos (Magister militum per Thrakias - PLRE II, Armatus [148f.]), Markian (Magister militum praesentalis mit erstrangigen dynastischen Verbindungen - siehe PLRE II, Fl. Marcianus 17 [717f.]) und der isaurische General Illous (PLRE II, Illus 1 [586-590]); auch ein gewisser Zuzos (PLRE II, Zuzus [1207]), ein Schwager der Augusta Verina, war an der Verschwörung beteiligt; zu seiner Karriere lassen sich allerdings keine näheren Aussagen treffen. 
auf dem Hebdomon. ${ }^{112}$ Basiliskos konnte sich allerdings nur ein Jahr in Konstantinopel halten. ${ }^{113}$ Zenons Rückkehr aus dem isaurischen Exil im darauffolgenden Jahr gelang unter anderem aufgrund des Seitenwechsels des Heermeisters Armatos, der von Basiliskos mit Truppen losgeschickt worden war, um den Konkurrenten aufzuhalten: Zenon sicherte sich Armatos' Unterstützung, indem er versprach, dessen Sohn zum Caesar zu erheben. Kurz nachdem ihm die Übernahme der Hauptstadt geglückt war, entledigte Zenon sich allerdings des unliebsamen Nachfolgers. ${ }^{114}$

479, nur wenige Jahre nach Zenons Rückkehr, rebellierte dessen Schwager, der General Markian, der bereits an der Usurpation des Basiliskos beteiligt gewesen war; Markian hatte nicht nur eine erfolgreiche militärische Karriere hinter sich, sondern auch dynastische Verbindungen: Er war der Enkel des gleichnamigen Ostkaisers Markian und Sohn des Westkaisers Anthemios. Außerdem war er mit Leontia, der jüngeren Tochter des Leon I., in deren zweiten Ehe verheiratet und somit Zenons Schwager. ${ }^{115}$ Unterstützung fand Markian bei dem Goten Theoderich Strabo, der mit seinen Einheiten von Thrakien aus Konstantinopel unter Druck setzte. ${ }^{116}$ Mit einer Gruppe aus Römern und Goten bestürmte Markian den Palast in Konstantinopel, konnte allerdings nach anfänglichen Erfolgen durch den Magister officiorum Illous, der die Palastgarden befehligte, zurückgeschlagen werden. ${ }^{117}$

Das Verhältnis zwischen den Landsleuten Zenon und Illous - bereits durch die Beteiligung des Letzteren an der Usurpation des Basiliskos angekratzt - erwies sich nur wenige Jahre später erneut als brüchig: Zenon schickte Illous 481 als Magister militum in den Osten, enthob ihn allerdings kurz darauf seiner Ämter, da er offenbar ein zu großes Risiko darstellte. Diese Herabsetzung beantwortete Illous mit offener Rebellion und begann, im Osten Truppen um sich zu scharen; Zenon schickte ihm den General Leontios entgegen. ${ }^{118}$ Doch Leontios lief zu Illous über und wurde mit dessen Unterstützung 484 im kilikischen Tarsos von der Augusta Verina gekrönt, die man

112 Theod. Lect. epit. 401; Vita Dan. 69; Mal. 15.2f.; Theoph. Conf. AM 5967 (De Boor 120f.); Vict. Tun. s.a. 475; Anon. Vales. 41; Marc. Com. Chron. ad a. 475; Prok. Bell. Vand. 1.7.18; Evagr. Hist. eccl. 3.3. Siehe dazu Pfeilschifter 2013, 536-544; Kosinski 2010, 79-82; Brandes 1993.

113 Sein Scheitern scheint vor allem seiner Religionspolitik zuzuschreiben zu sein, die in der Hauptstadt auf Ablehnung stieß, dazu siehe Pfeilschifter 2013, 564-584; vgl. Redies 1997.

114 Armatos handelte außerdem aus, dass ihm lebenslänglich das Amt des Magister militum übertragen wurde (Mal. 15.5; Theoph. Conf. AM 5969 [De Boor 124]). Zenon adoptierte darüber hinaus auch den Sohn des Theoderich des Amalers, um dessen Unterstützung gegen Theoderich Strabo sicherzustellen; auch diese Verbindung wurde bald wieder aufgelöst; siehe Jones 1964 I, 225.

115 PLRE II, Fl. Marcianus 17 (717f.). Gemäß den Quellen bediente er sich des Arguments, gegenüber Zenon im Vorrang zu sein, da seine Frau Leontia im Gegensatz zu Zenons Frau Ariadne im Purpur geboren worden war; siehe Joh. Ant. fragm. 303; Theoph Conf. AM 5971 (De Boor 126).

116 Leon I., Basiliskos und Zenon hatten Theoderich bereits wiederholt als Zugeständnis das Amt des Magister militum praesentalis verliehen; siehe PLRE II, Theodericus Strabo 5 (1073-1076); zu den wechselvollen Beziehungen der Römer zu den beiden Theoderichen (Theoderich Strabo und Theoderich der Amaler) siehe Jones 1964 I, 224-227.

117 Zum Usurpationsversuch des Markian siehe Pfeilschifter 2013, 551-554.

118 PLRE II, Leontius 17 (670f.). 
zuvor aus ihrem Exil herbeigeholt hatte. Die Krönung in der Provinz entfaltete allerdings in Konstantinopel keine Wirkmächtigkeit, wo Zenon weiterhin die Zügel in der Hand hatte. Leontios und Illous erlitten kurz darauf eine schwere Niederlage; nach mehrjähriger Belagerung in einer isaurischen Bergfestung wurden die beiden Männer schließlich hingerichtet. ${ }^{119}$

Als Zenon 491 verstarb, ohne einen Nachfolger designiert zu haben, sah eine Parteiung der hauptstädtischen Elite um den Praepositus sacri cubiculi Urbikios die Gelegenheit gekommen, sich der jahrzehntelangen Bevormundung durch alanische bzw. isaurische Heermeister zu entledigen. Die ,Wahl' eines Nachfolgers wurde formal der Augusta Ariadne, Zenons Witwe, übertragen, die sich für einen bereits in die Jahre gekommenen Palastbeamten, den Silentiarios Anastasios, entschied. Um wiederum einem Mann ohne eigenständige Autorität die nötige Legitimität zu verleihen, wurde er mit Ariadne verheiratet. ${ }^{120}$ Zenons Bruder Longinos, der das Amt des Magister militum praesentalis innegehabt, mehrmals den Konsulat bekleidet und sich Hoffnungen auf die Nachfolge seines Bruders gemacht hatte, ging angesichts dieser Entwicklung mit seinem gleichnamigen Landsmann, dem Magister officiorum Longinos, in den Widerstand. ${ }^{121}$ Isaurische Truppen wurden in Kleinasien zusammengezogen; bei der Schlacht von Cotyaeum 492 unterlagen sie allerdings den kaiserlichen Einheiten - der isaurische Einfluss auf Konstantinopel war damit gebrochen. ${ }^{122}$

Unter Anastasios lässt sich eine gewisse Stabilisierung des politischen Klimas beobachten; erst nach zwanzig Jahren an der Macht sah auch er sich mit Usurpationsgefahr konfrontiert: Im Zuge des Staurotheis-Aufstandes 512, bei dem die chalkedonensische Bevölkerung Konstantinopels sich gegen die kaiserliche Religionspolitik auflehnte, wurden Rufe nach einer Krönung des Areobindos laut. ${ }^{123}$ Areobindos entstammte der Familie des Aspar, war mit Anicia Juliana verheiratet, ihrerseits Nachfahrin der valentinianisch-theodosianischen Dynastie und Tochter des ehemaligen Westkaisers Anicius Olybrius; er hatte Kommandos als Magister militum und 506 den Konsulat belegt - in seiner Person verband sich also eine weiterhin mächtige Militärdynastie mit altem römischem Adel. Doch Areobindos entzog sich den Avancen der hauptstädtischen Bevölkerung; Anastasios’ Regierung war vorerst gesichert. ${ }^{124}$

Anastasios' späte Jahre auf dem Thron indes waren geprägt von weiteren Unruhen aus dem militärischen Sektor: Anlässlich mangelhafter Versorgung seiner Truppen

119 Zur Usurpation des Leontios siehe Kiel-Freytag 2010 und Pfeilschifter 2013, 557-560.

$120 \mathrm{Zu}$ Ariadne siehe Meier 2010.

121 Siehe PLRE II, Fl. Longinus 6 (689f.) und PLRE II, Longinus 3 (688). Zu den Mechanismen hinter der Erhebung des Anastasios siehe Meier 2009b, 63-75; Pfeilschifter 2013, 154-159.

122 Meier 2009b, 75-84.

123 Zum Staurotheis-Aufstand siehe Meier 2007a.

124 Siehe PLRE II, Fl. Areobindus Dagalaiphus Areobindus 1 (143f.); Begass 2018, 86; zu der Familie ebd., 29, 351-378. Über die Gründe für Areobindos' Zurückhaltung lässt sich nur spekulieren; Meier 2007a, 200 sieht einen Grund in dem Umstand, dass Anastasios Areobindos' Familie durch zahlreiche Gunsterweisungen an sich gebunden habe. 
erhob sich 513 der Comes foederatorum Vitalian, der in kurzer Zeit Thrakien, Moesia Secunda und Scythia unter seine Kontrolle brachte. In Opposition zu der von Anastasios betriebenen Kirchenpolitik, die auf einen Ausgleich mit den Miaphysiten abzielte, gab er sich als Verfechter des chalkedonensischen Glaubensbekenntnisses. Mit einem großen Heer rückte Vitalian bis zum Hebdomon vor, machte allerdings zu keinem Zeitpunkt Anstalten, sich selbst zum Kaiser erheben zu lassen. ${ }^{125}$ Nachdem die kaiserlichen Truppen mehrere Niederlagen erlitten hatten und Vitalian erneut auf Konstantinopel vorgerückt war, bahnte sich eine Einigung an: Anastasios verlieh Vitalian das Amt des Magister militum per Thrakias. Kurz darauf, im Jahr 515, eskalierte der Konflikt allerdings erneut. Nun wandte sich das Blatt: In Folge einer vernichtenden Niederlage zog Vitalian sich nach Thrakien zurück. Anastasios' Nachfolger Justin I. rehabilitierte Vitalian und ernannte ihn zum Magister militum praesentalis; als solcher setzte er sich weiter für das chalkedonensische Dogma ein und war an der Schlichtung des akakianischen Schismas beteiligt. Doch schien der Militär, der als Champion der Orthodoxie hohes Ansehen genoss, weiterhin als Bedrohung für den regierenden Kaiser wahrgenommen worden zu sein; 520 erlag Vitalian einem Mordkomplott, für den angeblich Justins Neffe Justinian verantwortlich war. ${ }^{126}$

Auch Anastasios ernannte zu Lebzeiten keinen Nachfolger, obwohl mit seinen Neffen Hypatios, Pompeios und Probos, die allesamt im Militär Karriere gemacht hatten, durchaus potentielle Kandidaten zur Verfügung standen. ${ }^{127}$ Anastasios' Bemühungen, seine Herrschaft gegenüber hohen Militärs zu stärken, hatte Erfolge gezeitigt: Zum Zeitpunkt seines Todes 518 gab es in Konstantinopel niemanden, der die politischen Prozesse nach individuellem Gutdünken lenken konnte, wie es Jahrzehnte zuvor Aspar getan hatte. Die Dynamiken, die sich nach dem Bekanntwerden von Anastasios' Tod entfalteten, lassen allerdings darauf schließen, dass mit der fortschreitenden Konzentration auf Konstantinopel als Dreh- und Angelpunkt kaiserlicher Herrschaft eine Bedeutungssteigerung der städtischen Garden einher gegangen war. Gemäß dem Zeremonienbuch wurde die Nachricht von Anastasios’ nächtlichem Tod zuerst an den Magister officiorum Keler (den Befehlshaber der Scholai) und den Comes excubitorum Justin weitergegeben, die ihre Einheiten formieren konnten, bevor sich am nächsten Morgen die restlichen Würdenträger im Palast zusammenfanden. ${ }^{128}$ Anders als 491, als die Verantwortung für die Wahl eines Nachfolgers formal an die Augusta Ariadne als Vertreterin der kaiserlichen Familie weitergegeben werden konnte, stand 518 keine Person mit vergleichbarer Autorität zur Verfügung. Die

125 Zu diesem Zeitpunkt muss klar gewesen sein, dass eine Krönung außerhalb Konstantinopels nicht die erhoffte politische Wirkmächtigkeit entfalten würde - zumindest dann, wenn der regierende Kaiser in Konstantinopel noch fest im Sattel saß. Laut einiger Quellen war Vitalian zuvor während des Staurotheis-Aufstandes in Konstantinopel 512 zum Kaiser akklamiert worden, siehe Meier 2007a, 167 f.; dies zog allerdings offenbar keine Folgen nach sich.

126 Zur Revolte des Vitalian siehe Kaegi 1981, 92f. und Meier 2007a, 203-209.

127 PLRE II, Fl. Hypatius 6 (577-581); Pompeius 2 (898f.); Fl. Probos 8 (912f.).

128 De cerim. 1.93. 
maßgeblichen Impulse der Entscheidungsfindung kamen von Seiten der bewaffneten Garden, während sich die versammelten Senatoren angesichts der Vereinzelung von Interessen als nicht handlungs- bzw. entscheidungsfähig erwiesen. In Palast und Hippodrom entfaltete sich eine chaotische Dynamik, die von den konfligierenden Initiativen der Garde-Einheiten bestimmt wurde. Nachdem verschiedene potentielle Kandidaten aus deren Reihen ins Spiel gebracht worden waren, machte schließlich der Comes excubitorum Justin selbst das Rennen. ${ }^{129}$

Unter Justin I. kam es wieder zu einer Designation: Ab wann genau Justins Neffe Justinian, der 518 bereits als Candidatus in den kaiserlichen Garden gedient hatte, ${ }^{130}$ zum Nachfolger seines Onkels Justin aufgebaut wurde, ist in der Forschung umstritten. ${ }^{131}$ Festzuhalten sei zumindest, dass Justinian kurz nach 518 in das einflussreiche Amt des Magister militum praesentalis befördert wurde. Ob er als solcher tatsächlich Truppen ins Feld führte, ist unklar; die Vollmachten, die aus einer derartigen Stellung erwuchsen, sind allerdings nicht zu unterschätzen. ${ }^{132}$ Bei Justins Tod 527 folgte Justinian, der kurz davor zum Augustus erhoben worden war, seinem Onkel jedenfalls reibungslos nach. ${ }^{133}$

In der Forschung herrscht in der Regel Konsens dahingehend, dass Justinian den militärischen Sektor weitestgehend im Griff hatte. ${ }^{134}$ Dennoch war auch Justinians Herrschaft einigen Bewährungsproben ausgesetzt, besonders während des sog. NikaAufstandes: Im Jahr 532 eskalierten Auseinandersetzungen mit der hauptstädtischen Bevölkerung in tagelangen Aufständen und der Zerstörung des Stadtzentrums. Justinians Rückhalt in Konstantinopel bröckelte; im Hippodrom, wo sich die Bevölkerung sowie einige Senatoren versammelt hatten, kam es gar zur Krönung eines alternativen Kandidaten. Dieser Kandidat, Hypatios, war nicht nur der Neffe des verstorbenen Kaisers Anastasios, sondern konnte auch auf eine erfolgreiche militärische Karriere

$129 \mathrm{Zu}$ Justin und seiner Karriere vor seiner Ernennung zum Comes excubitorum siehe Croke 2005b, 145f. und PLRE II, Iustinus 4 (648-651): In der Auseinandersetzung des Anastasios mit den Isauriern hatte Justin als Befehlshaber des Feldheeres gedient, außerdem wurde er gegen die Perser eingesetzt und war an der Niederschlagung der Revolte des Vitalian beteiligt. Börm 2013, 80 dagegen sieht Justin als „Kandidat des Hofes, nicht der Armee“; siehe zur Erhebung Jones 1964 I, 267 f.; Trampedach 2005, 281, 286; Pfeilschifter 2013, 165-175.

130 De cerim. 1.93.

131 Die These, Justinian habe seit der Krönung Justins die Zügel in der Hand gehabt, bleibt dahingestellt; siehe dazu ausführlich Croke 2007.

132 Börm 2013, 80 sieht Justinian eher als Zivilisten denn als Vertreter des militärischen Sektors; vgl. allerdings Koehn 2018, der 56-67, der Justinians militärischen Hintergrund betont; Lee 2007, 71.

133 PLRE II, Fl. Petrus Sabbatius Iustinianus 7 (645-648); als einzige zeitgenössische Quelle gibt Victor von Tununna (ad. a. 525) an, Justin habe Justinian bereits im Jahr 525 zum Caesar erhoben, bevor dann 527 die Krönung zum Augustus erfolgte; siehe dazu Croke 2007, 43-55.

134 Siehe dazu oben 48f. Unter Justinian wurden mindestens zwei der amtierenden Comites excubitorum gewaltsam aus dem Weg geschafft (siehe Croke 2005b, 146), was zeigt, dass er darum bemüht war, Kontrolle über die Garden zu halten. 
zurückblicken. ${ }^{135}$ Allein mit Hilfe der aus dem Osten zurückgekehrten Truppen unter der Führung des Generals Belisar, die im Hippodrom ein Massaker anrichtete, konnte Justinian die Lage in der Stadt wieder unter Kontrolle bringen; Hypatios wurde gemeinsam mit seinem Bruder Pompeios hingerichtet. ${ }^{136}$

Im Nachklang des Nika-Aufstandes konnte Justinian seine Stellung zwar wieder sichern, sah sich allerdings weiterhin den Ambitionen hoher Militärs ausgesetzt. Im Jahr 549 kam es zu einer Verschwörung um den armenischen General Artabanes. ${ }^{137}$ Von den Persern zu den Römern übergelaufen, war Artabanes bis zum Magister militum per Africam, Magister militum praesentalis und Comes foederatorum aufgestiegen. Nachdem er in Afrika entscheidende militärische Erfolge hatte erringen können, kehrte er nach Konstantinopel zurück und versuchte, durch die Verbindung mit Justinians Nichte Praeiecta die Einheirat in die kaiserliche Familie zu erwirken. Justinian und Theodora taten allerdings alles, um die Hochzeit zu verhindern. ${ }^{138}$ Aus Groll über die Zurückweisung schloss sich Artabanes einer Verschwörung an, die vom armenischen Adligen Arsakes ${ }^{139}$ angestoßen worden war. Ziel soll es gewesen sein, Germanos, einen weiteren Neffen Justins und somit Cousin Justinians, an dessen Stelle zum Kaiser zu erheben. ${ }^{140}$ Germanos, der zu diesem Zeitpunkt bereits auf eine illustre militärische Karriere zurückblicken konnte, erwies sich allerdings als loyal gegenüber Justinian; die Verschwörung wurde aufgedeckt. ${ }^{141}$

135 Hypatios hatte auf mehreren Kommandos als Magister Militum gedient, siehe PLRE II, Fl. Hypatius 6 (577-581) und Begass 2018, 146-153; ausführlich zu Hypatios Meier $2014 a$.

136 Justinian nutzte den Nachklang des Aufstandes, um unliebsame Männer kaltzustellen und die hauptstädtische Elite nach seinem Gutdünken umzustrukturieren. Zum Nika-Aufstand Meier 2003b, der die These aufstellt, Justinian habe die Eskalation inszeniert, um die Opposition innerhalb der hauptstädtischen Elite erst bloßzustellen und dann zu beseitigen; vgl. Greatrex 1997; Leppin 2011, 142 148; Pfeilschifter 2013, 178-210; Brandes 2014.

137 PLRE III, Artabanes 2 (125-130). Auch hier ist die Terminologie wieder irreführend; etwa Börm 2013, 80 f.: „coup d'état, der 549 aus einer Verschwörung am Hof hervorging“. Die Verschwörung spielte sich zwar am Hof ab, aber die wichtigsten Protagonisten gehörten dem militärischen Sektor an. 138 Praeicta (PLRE III, Praeiecta 1 [1048f.]) war zuvor mit Areobindus verheiratet gewesen (PLRE III, Areobindus 2 [107-109]), dem Magister militum per Africam, der der Revolte des Guntarith zum Opfer fiel. Artabanes gelang es, Guntarith zu beseitigen und die Ordnung im römischen Afrika wiederherzustellen; daraufhin forderte er Areobindus' Witwe zur Frau. Anstatt mit Artabanes wurde Justinians Nichte allerdings schnell mit einem gewissen Johannes (PLRE III, Ioannes 63 [665]) verheiratet, einem Verwandten des Anastasios, der abgesehen von seinem familiären Hintergrund nicht besonders herausstach und keine wichtigen Ämter (weder militärische noch zivile) bekleidet hatte - und demnach dem Kaiser kaum gefährlich werden konnte.

139 PLRE III, Arsaces (123f.); aus dem Haus der Arsakiden.

140 PLRE II, Germanus 4 (505-507).

141 Zu der Verschwörung siehe Meier 2003a, 261-264; Leppin 2011, 281f.; Pfeilschifter 2013, 467. Artabanes wurde von Justinian seiner Ämter enthoben, kurz darauf allerdings wieder als Magister militum per Thracias nach Sizilien geschickt. Ein weiteres erfolgloses Mordkomplott gegen Justinian im Jahr 562 (siehe Meier 2003a, 264- 269 und Pfeilschifter 2013, 467) scheint auf den ersten Blick anders gelagert, da nun Männer aus dem zivilen Bereich als Protagonisten in den Vordergrund treten, genauer gesagt geradezu dubiose Gestalten, die sich nicht einmal durch besondere Nähe zum Kaiser aus- 
Als Justinian im Jahr 565 verstarb, ohne einen Nachfolger designiert zu haben, kam mit dessen Neffen Justin II. nach Anastasios der einzige Kaiser des 5. und 6. Jahrhunderts an die Macht, der vor seiner Erhebung keine militärische Funktion ausgefüllt hatte; stattdessen hatte er das zivile Amt des Curopalates, des Vorstehers des kaiserlichen Palastes, bekleidet. ${ }^{142}$ Angesichts Justinians Tod brachte eine Delegation aus Senatoren und Palastbeamten, angeführt von dem Praepositus sacri cubiculi Kallinikos, Justin und seine Ehefrau Sophia, eine Nichte der verstorbenen Kaiserin Theodora, des Nachts unter großer Eile in den Palast, wo am nächsten Tag die Krönung vollzogen wurde. Die Exkubitoren und ihr Comes Tiberios, stationiert an den Eingängen des Palastes, deckten die nächtliche Initiative. ${ }^{143}$ Am nächsten Tag sah sich die städtische Öffentlichkeit mit vollendeten Tatsachen konfrontiert, erhob allerdings keinen Einspruch, sondern stimmte in den Jubel ein. ${ }^{144}$ Doch die Vormacht des städtischen Palastumfeldes war fragil: Die Zielstrebigkeit, mit der die Krönung des Justin II. am Tag nach Justinians nächtlichem Tod im Palast vollzogen wurde, ist vor dem Hintergrund zu verstehen, dass mit dem gleichnamigen Justin, einem erfahrenen General und Sohn des Germanos, Justinians Cousin, ein weiterer vielversprechender Kandidat für den Thron zur Verfügung stand. Im entscheidenden Moment 565 befand sich dieser jedoch nicht in der Hauptstadt, sondern kommandierte die römischen Truppen an der Donau. Nach seiner Krönung beorderte Justin II. seinen Namensvetter nach Konstantinopel zurück, stellte ihn erst unter Hausarrest und exilierte ihn schließlich nach Ägypten, wo er verstarb. Welches Risiko der General für die Stabilität von Justins Herrschaft darstellte, ist damit offenkundig. ${ }^{145}$

Dass die Bedeutung der städtischen Garden und ihrer Kommandeure zum Ende des 6. Jahrhunderts weiter anstieg, machte sich unter Justin II. erneut bemerkbar. 574 adoptierte dieser den Comes excubitorum Tiberios und erhob ihn zum Caesar; die Quellen bringen diesen Schritt mit Justins fragiler psychischer Verfassung in Verbindung: Die Nachricht von der Eroberung der Grenzfestung Dara durch die Perser habe den Kaiser in eine Nervenkrise gestürzt, aufgrund derer er den Regierungsgeschäften nicht mehr gerecht werden konnte. Gemeinsam mit Justins Ehefrau Sophia übernahm

zeichneten - der Bankier Markellos, der Musiker Ablabios und Sergios, Neffe des Senators Aitherios (im Amt des Curator divinae domus Antiochi; PLRE III, Aetherius 2 [21f.]). Die Aufklärung des Komplotts führte dazu, dass Belisar unter der Begründung, Mitglieder seines Stabes seien an der Verschwörung beteiligt gewesen, unter Hausarrest gestellt, ein halbes Jahr später aber wieder rehabilitiert wurde. Dieser Umstand wirft den Verdacht auf, dass es bei der ganzen Angelegenheit nicht so sehr um die dubiosen Verschwörer ging, sondern darum, Justinians erfolgreichsten General wieder einmal für eine gewisse Zeit kaltzustellen.

142 Zum Amt des Curopalates siehe Ma. Whitby 1987, 469-476. Nach der Justins Krönung wurde sein Schwiegersohn Baduarius in das Amt des Curopalates erhoben (PLRE III, Baduarius 2 [164f.]).

143 Goripp, der mit seinem In laudem Iustini minoris einen ausführlichen Bericht der Krönung liefert, widmet Tiberios in diesem Zusammenhang ganze 13 Verse (1.212-1.225); zur Bedeutung der Exkubitoren siehe Av. Cameron 1976a, 138; Croke 2005b, $147 \mathrm{f}$.

144 Siehe Mi. Whitby 2000a, 86f.; zur Krönung des Justin II. siehe Trampedach 2005, $282 \mathrm{f}$.

145 PLRE III, Iustinus 4 (750 - 754); Börm 2013, 81. 
Tiberios die Regierung. Kurz vor Justins Tod 578 erfolgte Tiberios’ Proklamation zum Augustus. ${ }^{146}$

Tiberios' Herrschaftsantritt verlief vergleichsweise reibungslos; allerdings sah auch er sich mit einer über Generationen gewachsenen Militärelite konfrontiert, genauer gesagt der Familie des Germanos, die - im Gegensatz zu ihm - mit der justinianischen Dynastie blutsverwandt war. Nach der Ermordung von Germanos' älterem Sohn Justin ging aus dieser Familie mit dem jüngeren Sohn Justinian ein weiterer Störfaktor für den regierenden Kaiser hervor. Unter Justin II. und Tiberios bekleidete Justinian - wie sein Bruder und Vater zuvor - höchste militärische Kommandos und wurde schließlich in dem erneut entflammten Perserkrieg eingesetzt. Als seine Kampagnen nicht den erhofften Erfolg zeitigten, rief Tiberios ihn ab und setzte stattdessen den Comes excubitorum Maurikios - seinen späteren Nachfolger auf dem kaiserlichen Thron - als Oberbefehlshaber gegen die Perser ein. Gemäß einer nur in westlichen Quellen erhaltenen Tradition wurde zweimal der Versuch unternommen, Justinian an Stelle des Tiberios auf den Thron zu bringen, gar mit Unterstützung der Augusta Sophia. ${ }^{147}$

Auch Tiberios sorgte bereits zu Lebzeiten für seine Nachfolge. Am 5. August 582 erhob er zwei Männer in den Rang des Caesar: einen Germanos, der zu dieser Gelegenheit Tiberios' ältere Tochter Charito heiratete, und Maurikios, der die jüngere Tochter Konstantina ehelichte. Maurikios bekleidete seit 574 das Amt des Comes excubitorum und hatte sich als Oberbefehlshaber im Perserkrieg ausgezeichnet. Germanos' Hintergrund ist undeutlich; allerdings scheint auch er ein Kommando als Magister militum bekleidet zu haben. ${ }^{148}$ Die Vermutung liegt nahe, dass er der Familie des bereits genannten Germanos, des Neffen des Justin I., entstammte - genauer gesagt, dass es sich bei ihm entweder um Germanos' Sohn oder Enkel handelte. ${ }^{149}$ Folgt

146 Zu Tiberios siehe PLRE III, Tiberius Constantinus 1 (1323-1326); außerdem Jones 1964 I, 304-306; zur Sukzession siehe Mi. Whitby 2000a, 94 f. Das Verhältnis zwischen Justin und Tiberios war offenbar bereits vor 565 ein enges gewesen. Justin förderte den jungen Tiberios, dem dank seines einflussreichen Gönners eine steile Karriere beschieden war. Nach Justins Krönung blieb Tiberios im Amt des Comes excubitorum und wurde darüber hinaus als Oberbefehlshaber in den Krieg gegen die Avaren geschickt; $\mathrm{zu}$ Justin II. und Tiberios siehe unten S. $69 \mathrm{f}$.

147 PLRE III, Iustinianus 3 (744-747). Obwohl die genauen Abläufe im Dunkeln bleiben, spricht doch meiner Meinung nach nichts dagegen, dahinter authentische Hinweise auf einen weiterhin schwelenden Machtkampf zu sehen; dazu siehe unten $69 \mathrm{f}$.

148 Theophanes (AM 6074 [252]) bezeichnet ihn als strategos, also mit dem griechischen Begriff für Magister militum.

149 Zwei Kandidaten stehen hier zur Debatte: Nach dem Tod seiner ersten Frau heiratete der ältere Germanos die ostgotische Prinzessin Matasuentha, mit der er einen Sohn, Germanos, zeugte (PLRE III, Germanos 3 [528]). Den Namen Germanos trug allerdings auch ein Enkel des älteren Germanos, nämlich der Sohn von dessen Sohn aus erster Ehe, Justinian, dessen Unstimmigkeiten mit Tiberios oben bereits erwähnt wurden (PLRE IIIB, Germanos 5 [529].) Greg. Tour. Hist. Frank. 5.30 schreibt, dass es nach der Beilegung des Zwistes zischen Tiberios und Justinian Pläne gegeben habe, Justinians Sohn mit Tiberios' Tochter zu verheiraten; der Plan sei dann allerdings laut Gregor nicht zur Umsetzung gekommen. 
man dieser Identifikation, offenbart sich der anhaltende Einfluss von Germanos' Familie in Konstantinopel: Tiberios kam nicht umhin, ihren Spross, der selbst in höchste militärische Ränge aufgestiegen war, in der Sukzession zumindest in Betracht zu ziehen. Von den beiden Männern wurde schließlich allein Maurikios am 13. August zum Augustus befördert; als Tiberios am folgenden Tag verstarb, folgte ihm Maurikios scheinbar ohne Komplikationen nach. Über das Schicksal des Germanos schweigen die Quellen weitestgehend. ${ }^{150}$

Zwischenfazit: Mit dem kursorischen Überblick über die politischen Dynamiken des 5. und 6. Jahrhunderts hoffe ich gezeigt zu haben, dass hohe militärische Funktionsträger sowie die städtischen Garden maßgeblichen Einfluss auf die monarchische Sukzession ausübten. ${ }^{151}$ Der militärische Sektor sollte somit als ein integraler Teil des politischen Systems Konstantinopel verstanden und untersucht werden. Die Mechanismen monarchischer Sukzession lassen sich folgendermaßen zusammenfassen: Nachdem die theodosianische Dynastie mit dem Tod des Theodosios II. ein Ende genommen hatte, bestimmten im 5. Jahrhundert Magistri militum wie Aspar und Zenon, deren Familien oft von einem nichtrömischen bzw. provinzialen Hintergrund über den Dienst im römischen Heer in höchste politische Sphären aufgestiegen waren, über die Besetzung des Thrones. Diese Entwicklung spiegelt zu einem gewissen Grad die Situation im Westen wider, wo den militärischen Funktionsträgern allerdings ungleich größere Handlungsspielräume zur Verfügung standen. ${ }^{152}$ Nach Zenons Tod konnte sich zwischenzeitig eine zivile Palastgruppierung mit ihrem Kandidaten Anastasios durchsetzen. Mit der Konzentration auf den hauptstädtischen Interaktionsraum ging im 6. Jahrhundert eine Bedeutungssteigerung der Palastgarden einher; die Comites excubitorum, die Befehlshaber des von Leon I. neu gegründeten Elitecorps, kristallisierten sich als prominenteste Akteure heraus - Justin I., Tiberios und Maurikios hatten vor ihrer Krönung dieses Amt bekleidet.

Das dynastische Prinzip erwies sich hinsichtlich monarchischer Sukzession weiterhin als relevant, war allerdings flexibel anwendbar. Angesichts der Ermangelung leiblicher Söhne wurden strategische Heiratsallianzen zwischen der Kaiserfa-

150 Nur Joh. Nik. 94.26 gibt an, „owing to his huminilty of heart he refused to be emperor”. Ein Germanos trat im Jahr 602 noch einmal ins Rampenlicht, siehe unten S. 84-92. Die Gründe dafür, dass Maurikios letztendlich das Rennen machte, sind schwer zu bestimmen; seine Reputation als erfolgreicher Persien-General mag ihm zuträglich gewesen sein. Mango/Scott 1997, 374 Anm. 4 geben an, Germanos sei zu diesem Zeitpunkt „governor of Africa” gewesen und habe daher einen geographischen Nachteil gegenüber Maurikios gehabt; diese Verbindung überzeugt allerdings nicht, siehe Pfeilschifter 2013, 140 mit Anm. 43.

151 Vgl. Trampedach 2005, 288: „Wie gelangte ein Kandidat in den Palast, wenn er beim Tod des Kaisers nicht schon darin saß (also designiert worden war)? Von größter Bedeutung war das militärische Kapital, über das er verfügen konnte.“ Allerdings betont Trampedach ebd. 288f. auch die Bedeutung der Palastbeamten und des Senates.

152 Die Überwältigung der weströmischen Kaiser durch barbarische Heermeister; siehe zusammenfassend Börm 2013, 76; außerdem McEvoy 2013. Zu den weströmischen Heermeistern siehe O’Flynn 1983; Henning 1999; Kuhoff 2012; Poguntke 2016. 
milie und prominenten Individuen geschlossen, um Kandidaten gezielt aufzubauen (Zenon, Maurikios) bzw. diese nach einer Thronvakanz ex post mit der nötigen Legitimität zu versehen (Leon I., Anastasios); dabei wird die Bedeutung weiblicher Mitglieder des Kaiserhauses, wie der Augusta Ariadne, deutlich. ${ }^{153}$ Wollten hohe Militärs die Sukzession nach ihren Interessen beeinflussen, so geschah dies bevorzugt, indem sie versuchten, die Einheirat in die kaiserliche Familie zu erzwingen und dadurch eine Designation (z. B. die Erhebung zum Caesar) zu erwirken - entweder ihre eigene oder die ihres Sohnes. ${ }^{154}$ Aspar konnte seine Ansprüche zumindest zeitweise gegenüber Leon I. geltend machen; die Ambitionen des Artabanes beinahe ein Jahrhundert später scheiterten an dem entschiedenen Widerstand Justinians. Tiberios sah sich gezwungen, gleich zwei Kandidaten mit seinen Töchtern zu verheiraten und in diesem Zuge zum Caesar zu erheben. Dass relativ viele Kaiser (Theodosios II., Markian, Zenon, Anastasios, Justinian) verstarben, ohne einen Nachfolger aufgebaut zu haben, lässt sich damit erklären, dass eine vorzeitige Designation die Gefahr einer Marginalisierung des Senior Augustus mit sich brachte. ${ }^{155}$

In der Forschung wurde wiederholt angemerkt, dass alle Usurpationen bzw. Usurpationsversuche im oströmischen Reich von Mitgliedern der Senatsaristokratie bzw. ehemaligen Konsularen ausgingen. ${ }^{156}$ Diese Beobachtung ist durchaus korrekt; der Sachverhalt kann allerdings noch präziser gefasst werden: Männer, die dem Kaiser ernsthaft gefährlich werden bzw. ihn gar stürzen konnten, waren allesamt auf dem militärischen Karrierepfad in die hauptstädtische Elite aufgestiegen; es handelte sich um ehemalige Magistri militum, die als Illustres zum politischen Establishment Konstantinopels gehörten und oft gar mit den höchsten Ehren eines Patrikios bzw. Konsuls ausgezeichnet worden waren. Die Initiative musste gar nicht einmal unbedingt von ihnen direkt ausgehen; in den seltenen Fällen, in denen die hauptstädtische Bevölkerung einen konkreten Kandidaten forderte, handelte es sich immer um Männer mit militärischem Hintergrund (Areobindos, Hypatios). Obwohl auch zivile Funktionsträger wie die Praefecti praetorio ihren Einfluss geltend machen konnten, obwohl sich vor allem die Palastbeamten durch einen außerordentlichen Grad an

$153 \mathrm{Zu}$ Ariadne siehe Meier 2010.

$154 \mathrm{Zu}$ den familiären Netzwerken, die durch derartige Verbindungen entstanden, siehe Demandt 1980 und Schwarcz 2003. Im Westen passierte es wesentlich öfter, dass hohe Militärs ihre Machtposition durch die Einheirat in die Kaiserfamilie zementierten, so geschehen etwa im Falle des Stilicho, der Flavia Serena, die Nichte des Theodosios I. heiratete. Dass die kaiserliche Familie das Risiko, das von derartigen Verbindungen ausging, wahrnahm und versuchte es einzuhegen, zeigt das Beispiel der Pulcheria, der Schwester des Theodosios, die sich zur Jungfräulichkeit entschied; siehe Soz. 9.1.3: „Zuerst widmete sie Gott ihre eigene Jungfrauenschaft und erzog ihre Schwestern zur gleichen Lebensweise, um keinen anderen Mann in den Palast zu bringen und um jeden Anlass zu Eifersucht und

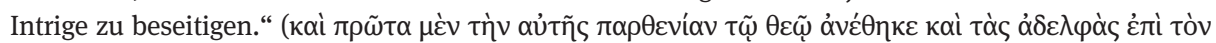

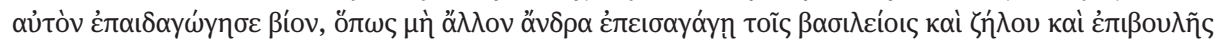

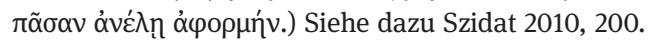

155 Siehe Trampedach 2005, 287 Anm. 35.

156 Meier 2002, 282; Pfeilschifter 2013, 452; Begass 2018, 4, 421; etwas differenzierter Szidat 2010, $257 \mathrm{f}$. 
Kaisernähe auszeichneten, ging von der zivilen Administration keine strukturelle Bedrohung für den Monarchen aus. Allein bei Thronvakanzen, wenn der regierende Kaiser verstorben war, ohne einen Nachfolger zu bestimmen, konnten bisweilen Männer aus dem direkten Palastumfeld ihren konkret räumlichen Vorteil, d.h. die Kontrolle über die Abläufe im Palast, nutzen, um durch zielstrebiges Handeln ihre Kandidaten durchzubringen; so geschehen bei den Erhebungen des Anastasios und des Justin II. ${ }^{157}$

Neben der Überwältigung des regierenden Kaisers und der offenen Usurpation sind noch weitere Formen der Einflussnahme aus dem militärischen Sektor zu beobachten: Mit Gehorsamsverweigerung in der Provinz konnten Feldherren den Kaiser unter Druck setzen und die Umsetzung der eigenen Interessen erzwingen. Vitalian etwa gelang es, seine Stellung durch die Revolte in der Provinz derart festigen, dass er wiederholt in höchste offizielle Kommandos gesetzt wurde. Angesichts der Zentralität Konstantinopels zeitigten Kaiserkrönungen in der Provinz allerdings keine nachhaltige Wirkung. ${ }^{158}$

\subsection{Ermächtigungsstrategien der Kaiser}

Die zentrale Herausforderung der sesshaften Kaiser des 5. und 6. Jahrhunderts bestand darin, den militärischen Sektor zu kontrollieren, anstatt von ihm kontrolliert zu werden. Konnte der Kaiser seine Hoheit über den militärischen Sektor nicht wahren, so lief er Gefahr, dass ihm die politischen Geschicke der Hauptstadt - bis hin zu Sukzessionsfragen - entglitten. Die Kaiser in Konstantinopel erwiesen sich als vergleichsweise resilient: Trotz einer strukturellen Abhängigkeit vom militärischen Sektor verkümmerte die oströmische Monarchie nie zu einer leeren Institution ohne Eigengewicht in politischen Entscheidungsprozessen. Auf den folgenden Seiten werde ich der Frage nachgehen, mit welchen Mitteln es den Kaisern gelang, sich gegenüber militärischen Funktionsträgern zu emanzipieren.

$157 \mathrm{Zu}$ Kaisern (bzw. Usurpatoren) mit zivilem Hintergrund - allerdings auch für den westlichen Reichsteil - vgl. Szidat 2010, 182-187 und 261-268; ebd. 267 wird betont, dass die „Interessen ziviler Amtsträger bei Thronvakanzen stärker bedroht [waren] als die der militärischen Kommandanten“, da sie Macht nur durch ihre institutionelle Stellung und nicht durch militärische Deckung ausüben konnten (vgl. ebd. 194); um sich abzusichern, galt es, einen Kandidaten auf den Thron zu bringen, der der bestehenden zivilen Führungsriege wohlgesonnen war.

158 Angesichts der Konzentration dieses Kapitels auf den militärischen Sektor wurde die Frage nach der Bedeutung der hauptstädtischen Bevölkerung für die Aushandlung und Festigung monarchischer Herrschaft bisher bewusst weitgehend ausgeklammert. In welchem Maße die Kaiser von der Akzeptanz dieser Gruppe abhängig waren, wurde in der Forschung oft betont, siehe etwa Pfeilschifter 2013, 294 354. In den Kapiteln 3.1 und 3.2 werde ich die Wechselwirkungen, die sich zwischen Impulsen des militärischen Sektors und der öffentlichen Stimmung in Konstantinopel entfalten konnten, eingehend besprechen. 
Die extremste Option der Gegenwehr von Seiten des Kaisers bestand darin, einen General, von dem ein akutes Risiko ausging, aus dem Weg zu räumen. Abgesehen von den prominentesten ,Opfern` kaiserlicher Ermächtigung, dem Alanen Aspar und dessen Söhnen, lassen sich eine Reihe weiterer Beispiele anführen: Vitalian, der Anastasios massiv in Bedrängnis gebracht hatte und erst unter Justin I. beseitigt wurde, und schließlich Justin, dessen Prestige als General seinem Verwandten und Namensvetter Justin II. gefährlich zu werden drohte. ${ }^{159}$ Einem derartigen Verfahren waren allerdings klare Schranken gesetzt; solange Funktionsträger sich nicht offen gegen den Kaiser stellten oder ihnen illoyales Verhalten bzw. Usurpationsabsichten zumindest plausibel unterstellt werden konnten, hatten die Kaiser kaum etwas gegen sie in der Hand. Vor dem Hintergrund des Ideals monarchischer Civilitas konnte willkürliches Verhalten gegenüber der hauptstädtischen Elite für den Kaiser zum Problem werden; trotz der Vereinzelung der oströmischen Aristokratie regte sich mitunter eine gewisse Standessolidarität, welche die einzelnen Vertreter zu einem gewissen Grad vor der Willkür des Kaisers schützte. Die Möglichkeit der Diffamierung des Kaisers als Tyrann und eines damit einhergehenden Akzeptanzverlustes lag allzu nahe. ${ }^{160}$ Henning Börm hat darauf aufmerksam gemacht, dass die oströmischen Kaiser zumindest in der ersten Hälfte des 5. Jahrhundert bisweilen einen subtileren Weg gingen, um ambitionierte Generäle aus ihrem näheren Umfeld zu entfernen: Sie schickten diese als Augusti in den Westen des Reiches - so geschehen bei Anthemios, dem Schwiegersohn des Kaisers Markian, und Anicius Olybrius, die angesichts ihrer herausgehobenen Stellung für Leon I. eine latente Bedrohung darstellten. ${ }^{161}$

Komplementär zu der Einhegung prominenter Individuen muss es den Kaisern darum gegangen sein, die Kontrolle über die Besetzung der höchsten Kommandos nicht nur nominell, sondern auch praktisch aufrecht $\mathrm{zu}$ erhalten, anstatt sich von einflussreichen Militärs die Personalentscheidungen diktieren $\mathrm{zu}$ lassen. Bemühungen des Kaisers, ein auf Patronagebeziehungen basierendes, loyales Umfeld zu schaffen, sind als Phänomen nicht per se bemerkenswert; für die sesshaften Monarchen bestand allerdings besondere Dringlichkeit, den militärischen Sektor an sich zu binden und die Autonomie hoher Funktionsträger so weit wie möglich zu beschränken. Indem sie die entscheidenden Kommandos mit engen Vertrauten besetzten, anstatt diese für ambitionierte Militärs zur Disposition zu stellen, konnten sie ihre Reichweite über die Mauern Konstantinopels hinaus sichern. So verwundert es

159 Siehe Lee 2007, 69f. und fürs 4. Jahrhundert ders. 2015, 116f. Im Westen des Reiches versuchte Valentinian III. sich eben dieser Methode zu bedienen: Er brachte - angeblich eigenhändig - den Heermeister Aetius um, wurde dann allerdings selbst von dessen Gefolgsleuten ermordet; dazu siehe Börm 2018, 99-104.

160 Zu dieser Problematik siehe Börm 2010, bes. 168-172; ähnlich Börm 2013, 72f.; zur hauptstädtischen Elite siehe auch Pfeilschifter 2012 und ders. 2013, 452-474. Vgl. den Fall des Phokas: Sein unsensibles Vorgehen gegenüber der hauptstädtischen Elite und der daraus resultierende Akzeptanzverlust trugen letztendlich zu seinem Sturz bei; dazu siehe unten Kap. 4.1.

161 Börm 2010, 165 f. 
kaum, dass im 5. wie im 6. Jahrhundert oft Verwandte des regierenden Kaisers in den wichtigen Heermeisterämtern installiert wurden - bisweilen trotz mangelnder militärischer Qualifikation. ${ }^{162}$ Ein loyales Umfeld erwirkten die Kaiser außerdem dadurch, dass sie Männer niedrigerer Herkunft in Ämter und Würden erhoben und damit ein Gegengewicht zu etablierten Kreisen und gewachsenen Machtstrukturen schufen. ${ }^{163}$ Alternativ konnten sie auf Personen zurückgreifen, die ihnen aufgrund ihrer sozialen Stellung nicht gefährlich werden konnten: Dass unter Justinian ausgerechnet ein Eunuch, Narses, zum bedeutenden Feldherren aufstieg, ist kaum ein Zufall, nachdem sich der General Belisar nicht zuletzt aufgrund seiner außerordentlichen Erfolge als Risikofaktor erwiesen hatte. ${ }^{164}$

Der sicherste Weg, sich gegenüber militärischen Funktionsträgern zu behaupten, lag allerdings in der Stärkung der monarchischen Position. Dass die Bindung an Konstantinopel den Kaisern, die nicht mehr persönlich in den Krieg zogen, alternative Betätigungsfelder eröffnete, wurde bereits erwähnt; die fortschreitende Sakralisierung der kaiserlichen Persona und die Liturgisierung der Interaktion mit der hauptstädtischen Bevölkerung bildeten im 5. und 6. Jahrhunderts ein Gegengewicht zu dem Druck, der von hohen militärischen Funktionsträgern ausging. ${ }^{165}$ Überblickt man das 5. und 6. Jahrhundert, so fällt indes auf, dass auch die sesshaften Kaiser an militärischer Repräsentation festhielten: Auf Münzen erschienen sie im Gewand des Feldherrn, des Imperators, die Namen besiegter Völker bildeten Teil ihrer Titulatur und sowohl materielle (z.B. Reiterstatuen im öffentlichen Raum) als auch ephemere Zeugnisse (Panegyrik) feierten sie als Sieger. ${ }^{166}$ Was auf den ersten Blick als Paradox anmutet, löst sich auf, wenn man die hier adressierten Dynamiken in die Überlegung einbezieht: In noch höherem Maße als ihre Vorgänger im Prinzipat bewegten sich die sesshaften Kaiser der Spätantike auf dem schmalen Grat zwischen der Anerkennung militärischer Erfolge, welche mit einer Statuserhöhung des jeweiligen Befehlshabers einherging, und der Wahrung kaiserlicher Autorität und Überlegenheit. Nicht allein die fortschreitende Sakralisierung führte zu einer Stabilisierung oströmischer Herr-

162 Siehe Lee 2007, 71; Olster 1993, 34f. fürs 6. Jahrhundert.

163 Diese Strategie verfolgte allen voran Justinian, selbst von bescheidener Herkunft; siehe Börm 2010, 182.

164 Börm 2010, 177 f.; ders. 2013, 86 Anm. 127. In diesem Zusammenhang mag auch die, vor allem im 5. Jahrhundert nachvollziehbare, Förderung nichtrömischer Feldherren gestanden haben, deren Griff nach dem Thron aufgrund ihrer Herkunft ausgeschlossen war. Die Sollbruchstelle dieser Strategie, nämlich der Umstand, dass es für die Kontrolle des Imperiums nicht unbedingt einer Krone bedurfte, zeigte sich in geringerem Maße im oströmischen, wesentlich deutlicher im weströmischen Reich, wo unmündige Kaiser sich barbarisch-stämmigen Feldherren ausgeliefert sahen, die schließlich die römische Monarchie abschafften; siehe etwa McEvoy 2013.

165 Diese Entwicklung wurde von Diefenbach 1996, 2002 herausgearbeitet; zuletzt zusammenfassend ders. 2109, 75f.; siehe außerdem Meier 2012 mit einem noch breiteren Überblick; fürs 6. Jahrhundert ders. 2016. Was genau die Forschung unter Sakralisierung des Kaisertums versteht, wird unten S. 198200 genauer diskutiert.

166 Lee 2007, 37-50; Aspekte kaiserlicher Repräsentation werden unten S. 197 f. genauer beleuchtet. 
schaft, sondern auch der Umstand, dass es den Kaisern in der Regel gelang, die von Generälen erfochtenen Erfolge vor einem hauptstädtischen Publikum auf die eigene Person zu übertragen. 498 zelebrierte Konstantinopel den Sieg der kaiserlichen Truppen über die isaurische Partei in Kleinasien: Longinos und Indes, die prominenten Anführer der Aufständischen, wurden in Ketten durch die Stadt bis in den Hippodrom geführt, wo der Kaiser Anastasios den unbestrittenen Mittelpunkt des Spektakels bildete. In ihren Panegyriken zeichnen Priscian und Prokop Anastasios, der weder vor noch nach seiner Krönung als Befehlshaber tätig gewesen war, mit Verweis auf glorreiche Feldherren der römischen Vergangenheit, wie etwa Pompeius Magnus, als Triumphator; den Generälen, die den Sieg gegen die Isaurier errungen hatten, bleibt in diesem Narrativ nur die Position der loyalen Untertanen. ${ }^{167}$ Im Zuge der Siegesfeierlichkeiten, welche sich nach Belisars Sieg über die Vandalen vor den Augen der hauptstädtischen Bevölkerung entfalteten, nahm nicht Belisar die Rolle des Triumphators ein, sondern Justinian, der als gottgleicher Herrscher im Kathisma des Hippodroms über dem Geschehen thronte und die eigentlichen Ehrungen empfing. Justinian als unumstrittener Mittelpunkt des Geschehens verflocht den Sieg über die Vandalen mit einer konsequenten, religiös konnotierten Überhöhung der eigenen Person; Belisar zeigte sich als ergebener Untertan. ${ }^{168}$

Triumphalismus bildete also weiterhin das Fundament monarchischer Herrschaft, auch wenn die Repräsentation des sieghaften Kaisers an die Parameter der hauptstädtischen Monarchie angepasst wurde: An die Stelle des charismatischen Kriegers trat spätestens mit der Niederlassung in Konstantinopel der ewige Sieger. Monarchische Sieghaftigkeit war nicht mehr an konkrete militärische Erfolge geknüpft - konnte demnach durch Niederlagen nicht geschmälert werden -, sondern entwickelte sich zu einer dem Kaiser von dem Moment seiner Krönung an inhärenten Qualität; konkrete Siege des römischen Heeres konnten diese Qualität noch akzentuieren. Solange die sesshaften Kaiser vor der Kulisse Konstantinopels ihre Vormachtstellung gegenüber den Generälen glaubhaft vermitteln konnten, solange die Idee von der Sieghaftigkeit des Imperiums an den regierenden Kaiser gebunden blieb,

167 Börm 2013, 69 f., 79 (zu den Generälen); zum Triumph des Anastasios außerdem Croke 2008 und McCormick 1986, 61. Vgl. allgemein zu spätantiken Siegesfeierlichkeiten McCormick 1986, 35-79; Pfeilschifter 2016; Diefenbach 2019.

168 Siehe zuletzt Diefenbach 2019, 92-100 mit Diskussion der These von Börm 2013, dass die Inszenierung primär dem Zweck gedient habe, Belisar vor der versammelten Bevölkerung Konstantinopels zu erniedrigen (siehe bes. ebd. 65); vgl. Pfeilschifter 2017, 459-461, bes. Anm. 9. Ähnlich wie Diefenbach und Pfeilschifter bin ich der Meinung, dass Börm den Aspekt der Demütigung Belisars überstrapaziert.Vgl. auch Meier 2019b; ders. 2002, $287 \mathrm{f}$. zum Triumph und 284f. zu der Bedrohung, die für Justinian von Belisar ausging (und zu dessen wechselvoller Karriere); es sei darauf hingewiesen, dass dem Belisar ein Jahr nach dem Vandalensieg der Konsulat verliehen wurde und er prunkvolle Spiele ausrichtete. Zu Triumphen römischer Feldherren in der Provinz siehe Pfeilschifter 2016, 455 457: Belisar in Antiochia, Johannes Troglita in Karthago. 
ließ sich die Bedrohung, welche vom militärischen Sektor ausging, zu einem gewissen Grad einhegen. ${ }^{169}$

\subsection{Die hauptstädtische Monarchie im späten 6. Jahrhundert}

In der Entwicklung der oströmischen Monarchie wird die Regierung Justinians von der Forschung in der Regel als Schlüsselphase gesehen. ${ }^{170}$ Mit der Rückeroberung des Westens konnte der Anspruch auf ein Imperium Romanum, welches das gesamte Mediterraneum umfasste, vorübergehend wiederbelebt werden. Justinians Herrschaft erwies sich zwar nicht als unumstritten, aber insgesamt doch als stabil. Zentrale Charakteristika der hauptstädtischen Monarchie, wie die fortschreitende Sakralisierung der kaiserlichen Persona und die Liturgisierung von Interaktionsformen, erreichten zwischen 527 und 565 einen vorläufigen Höhepunkt. Die spezifische Ausformung kaiserlicher Autorität, die Justinian über Jahrzehnte etablierte, hielt den vielfältigen Bedrohungen stand, mit denen er sich im Laufe seiner 38 Jahre währenden Regierung konfrontiert sah; dazu zählen kontingente Faktoren wie das Ausbrechen der Pest in Konstantinopel und dem gesamten Mittelmeerraum, aber auch innenpolitische Schwierigkeiten wie das andauernde Ringen um Einigung der verschiedenen christlichen Denominationen und eine kaiserliche Religionspolitik, die vor allem in den späten Jahren Justinians auf verstärkte Ablehnung stieß. Die Standards, die Justinian auf verschiedenen Feldern etablierte - auf dem sakralen Feld spricht Meier gar von einer folgenschweren Übersteigerung ${ }^{171}$-, spannten den Rahmen, innerhalb dessen seine Nachfolger ihre Regierung gestalten konnten. Das Erbe war kein leichtes: Einerseits mussten Justinians Nachfolger den über Jahrzehnte geformten Erwartungshaltungen gerecht werden; andererseits war jeder Kaiser - bedingt durch den meritokratischen Charakter römischer Monarchie - darauf bedacht, seiner Herrschaft ein eigenes Profil zu geben und sich gegenüber dem Vorgänger abzuheben.

Als Justin II. dem verstorbenen Justinian 565 auf den Thron folgte, stand er vor einer besonderen Herausforderung: Sein Onkel hatte ihn nicht persönlich als Nachfolger designiert; stattdessen war er, der vormalige Curopalates, von einer Parteiung im kaiserlichen Palast auf den Thron gehievt worden. ${ }^{172}$ Der Charakter von Justins Politik wird bereits in der Panegyrik des Goripp, die kurz nach der Krönung entstand, auf den Punkt gebracht: Beim Versuch, die junge Herrschaft mit der nötigen Legitimität zu versehen, diente der verstorbene Justinian sowohl im positiven wie auch im

169 Diefenbach 2019, bes. 70 weist außerdem darauf hin, dass in den Inszenierungen von Siegesfeierlichkeiten im 5. und 6. Jahrhundert Gott als Urheber von militärischem Erfolg herausgestellt wurde; mit einer derartigen Deutung wurde das charismatische Potential von Sieg nicht den Generälen überlassen.

170 Siehe etwa die Monographien von Meier 2003a und Leppin 2011.

171 Meier 2016.

172 Siehe oben S. 58. 
negativen Sinne als Referenzpunkt. Die Betonung eines besonderen Nahverhältnisses zu Justinian und der Verweis auf dynastische Kontinuität einerseits sowie explizite Kritik an dessen politischen Entscheidungen andererseits halten sich im Lob auf Justin II. die Waage. ${ }^{173}$ Parallel zu der literarischen Stilisierung Goripps lassen sich auch Justins praktische Maßnahmen entlang der Dichotomie von Anknüpfung und Abgrenzung beschreiben. Mit Blick auf den militärischen Sektor fällt dabei vor allem auf, dass Justin von der Politik seines Onkels abwich, die Feinde an den Reichsgrenzen durch umfangreiche Geldzahlungen in Schach $\mathrm{zu}$ halten, und stattdessen einen wesentlich konfrontativeren Kurs einschlug. Eine avarische Delegation, die sich in Konstantinopel einfand, um die von Justinian zugesicherten Zahlungen in Empfang zu nehmen, wurde von Justin harsch zurückgewiesen. Goripp wiederum nutzt die Schilderung dieses Aufeinandertreffens vor der beeindruckenden Kulisse des hauptstädtischen Palastes, um Justin - mit Verweisen auf typische Kategorien imperialer Sieghaftigkeit - als von Gott erwählten Garanten römischer Souveränität zu zeichnen. ${ }^{174}$

Auf dem Balkan zeitigte Justins konfrontative Politik vorübergehend Erfolg: Die Expansionsbemühungen der Avaren richteten sich nach Westen, anstatt weiterhin Thrakien zu beeinträchtigen; an der Ostgrenze dagegen hatte das kühne römische Vorgehen katastrophale Folgen. Vor dem Hintergrund des 50-jährigen Friedens, der 561/2 noch unter Justinian geschlossen worden war, entspann sich zwischen Justin und dem persischen Großkönig Chosroes I. ein Ringen um Einfluss und Oberhoheit in den gemeinsamen Grenzregionen. Die Aussicht auf eine Allianz mit den Türken, die von ihrem zentralasiatischen Standpunkt aus Interesse an der Machtkonstellation im kaukasischen Raum zeigten, mag römische Hoffnungen auf Machtzuwachs begünstigt haben. Schließlich bot der Appell armenischer Adliger an Konstantinopel, das

173 Vor allem die durch Justinians Politik geleerten Staatskassen werden von Goripp wiederholt thematisiert (Laud. Iust. 2.249-274). Kritik an Justinians Politik findet sich auch in Justins Gesetzgebung - Just. Nov. 148 pr.: „Denn als wir herausfanden, dass die Staatskasse mit vielen Schulden belastet und zum extremen Mangel getrieben war, haben wir sie von Last und Schwierigkeit befreit, indem wir die Schulden aus eigenen Mitteln zurückgezahlt haben. Außerdem haben wir auch die militärischen Angelegenheiten, bereits ruiniert durch den Mangel am Notwendigen, sodass das Gemeinwesen erschüttert wurde von Invasionen und unzähligen Einbrüchen der Barbaren, mit entsprechenden Korrekturen versehen, soweit es uns möglich war." (Fiscum enim cum multis debitis oneratum et ad extremam inopiam adactum inveniremus, in nos ipsos aere alieno recepto onere atque difficultate magna liberavimus. Deinde rem militarem rerum necessariarum penuria iam dilapsam, ita ut res publica barbarorum invasionibus irruptionibusque infinitis labefactaretur, quoad eius facere potuimus, idonea emendatione dignamur.) Dass Justin die von Justinian aufgenommenen Schulden nach seiner Krönung aus eigenen Mitteln zurückzahlte, wird auch in Gor. Laud Iust. 2.399-406 erwähnt. Außerdem belebte Justin wenige Monate nach seiner Krönung den Konsulat wieder, der unter Justinian zuletzt 541 besetzt worden war (siehe Gor. Laud. Iust. 4); zum Ende des Konsulates unter Justinian siehe Meier 2002.

174 Empfang der avarischen Delegation: Gor. Laud. Iust. 3.151-407, außerdem Menand. Prot. fragm. 14 und Joh. Eph. Hist. eccl. 6.24; siehe Kommentar bei Av. Cameron 1976a, 185f. Vgl. außerdem Av. Cameron 1980, bes. $71 \mathrm{zu}$ Justins Versuch, seine Herrschaft in der Stadt sichtbar zu machen. 
christliche Armenien bei seiner Behauptung gegen die Ausbreitung des zoroastrischen Feuerkultes zu unterstützen, ein willkommenes Argument, um entschieden gegen das sassanidische Reich vorzugehen. Vermeintliche persische Schwäche gab Justin 572 das Selbstbewusstsein, erneut Tributzahlungen einzubehalten; kurz darauf unternahmen römische Truppen erste Vorstöße in die Arzanene. Doch bevor nennenswerte Erfolge erzielt werden konnten, überquerte eine persische Armee unter persönlicher Führung des Großkönigs Chosroes I. den Euphrat, plünderte Syrien und nahm schließlich nach sechsmonatiger Belagerung die römische Grenzfestung Dara ein. Allein mithilfe erneuter hoher Geldzahlungen an Persien konnte ein Friedensschluss erwirkt werden. ${ }^{175}$

Dass sich ausgerechnet der Zivilist Justin II. als Kriegstreiber betätigte, Friedensschlüsse brach und ostentativ darum bemüht war, trotz hoher Risiken die römische Autorität gegenüber äußeren Feinden zu behaupten, ist bemerkenswert. Eine derartige Politik wird in der Regel als pragmatischer Versuch Justins plausibilisiert, die von Justinian stark in Mitleidenschaft gezogenen Staatsfinanzen nicht noch weiter durch Tributzahlungen zu strapazieren. ${ }^{176}$ Die hier gewählte Perspektive legt allerdings eine alternative bzw. ergänzende Interpretation nahe: Justin, der vor seiner Krönung keinerlei militärischen Erfahrung hatte sammeln können, versuchte vom Palast aus, mit einer konfrontativen Politik sein kaiserliches Profil zu schärfen und dem militärischen Sektor den eigenen Stempel aufzudrücken. Nachdem er bereits die Avaren bei der Audienz vor der versammelten hauptstädtischen Elite abgekanzelt hatte, setzte Justin nun ein weiteres klares Zeichen in der Beziehung zum römischen Erzfeind an der östlichen Reichsgrenze. ${ }^{177}$

Mit den Persern hatte Justin einen besonderen Gegner gewählt. Das Verhältnis zwischen dem sassanidischen Persien und Rom lässt sich grob in drei Phasen einteilen: Nach der Etablierung der sassanidischen Dynastie im frühen dritten Jahrhundert standen die beiden Nachbarn über mehr als ein Jahrhundert in beinahe konstantem Konflikt; erst nach dem Perserfeldzug Julians beruhigte sich das Verhältnis. Im späten vierten und fünften Jahrhundert sind kaum bewaffnete Aufeinandertreffen zu verzeichnen; stattdessen formalisierten sich die diplomatischen Kontakte, geprägt von gegenseitiger Anerkennung und Wertschätzung zwischen den beiden Reichen, die jeweils mit der Sicherung anderer Grenzzonen beschäftigt waren. Ab dem frühen sechsten Jahrhundert eskalierten die Konflikte allerdings erneut: 540 brach Chosroes I. den mit Justinian ausgehandelten Ewigen Frieden und verheerte die römischen Ostprovinzen. Seitdem trat kaum mehr dauerhafte Ruhe ein. Der 50-jährige Friede von 561/2 musste auf römischer Seite durch hohe Tributzahlungen erkauft

175 Zu Justins Außenpolitik siehe Mi. Whitby 2000a, 90 -94; Jones 1964 I, 304-306; zum erneuten Ausbruch des Perserkrieges siehe Mi. Whitby 1988, 250 - 258 und Turtledove 1983.

176 Mi. Whitby 1988, 251.

177 Justin schickte erst einmal seinen Neffen Markian als Magister Militum gegen die Perser; PLRE IIIB, Marcianus 7 (821-823). 
werden. ${ }^{178}$ Während im dritten und vierten Jahrhundert Konflikte regelmäßig von römischer Seite provoziert worden waren - ein Sieg über die Perser versprach dem regierenden Kaiser enormen Prestigegewinn -, büßte militärische Konfrontation mit den Sassaniden, wie Henning Börm zuletzt argumentiert hat, für die sesshaften Kaiser an Attraktivität ein: $\mathrm{Zu}$ hoch waren die damit einhergehenden Risiken, nicht zuletzt die mögliche Exponierung eines siegreichen Generals, welcher die Autorität des Kaisers hätte beeinträchtigen können. ${ }^{179}$

Mit seiner riskanten Aggression gegen Persien hatte Justin II. in der Tat zu hoch gepokert; die Folgen der römischen Niederlage waren umso schwerwiegender: Die Nachricht vom Verlust Daras stürzte den Kaiser gemäß den Quellen in eine Nervenkrise; angesichts seiner eigenen Regierungsunfähigkeit habe er den loyalen Tiberios, seinen Comes excubitorum, 574 zum Caesar erhoben. ${ }^{180}$ Während die Forschung dieser Erzählung in der Regel recht unkritisch folgt, ${ }^{181}$ eröffnet sich vor dem Hintergrund dieses Kapitels eine alternative Deutungsmöglichkeit; dabei ist allerdings zu betonen, dass es sich beim Folgenden um eine Hypothese handelt, die nicht im Detail verifiziert werden kann. Wenige Jahre nach seiner Krönung scheint Justins Rückhalt in Konstantinopel zu bröckeln begonnen zu haben. Innenpolitisch sorgte seine rigide Sparpolitik für Missbilligung; seine religionspolitischen Vorstöße zeitigten nicht den gewünschten Erfolg. ${ }^{182}$ Nachdem das Scheitern seiner kühnen Maßnahmen im militärischen Bereich mit dem Debakel am Euphrat besiegelt worden war, konnte Justin II. sich - so die Hypothese - nicht mehr länger souverän an der Spitze der politischen Hierarchie halten und musste Tiberios das Feld räumen. Tiberios’ Machtbasis lag in der militärischen Kontrolle des Palastes; seine Entsendung als Befehlshaber in die Provinz hatte seinen Einfluss noch ausgebaut. Als er den Rückhalt des hauptstädtischen Umfeldes verspielt hatte, scheint Justin II. keine andere Wahl mehr geblieben zu sein, als dem aufstrebenden Tiberios das Feld zu räumen und seine letzten Jahre als lame duck ohne Entscheidungshoheit im Palast zu fristen. ${ }^{183}$ Anstatt offener Usur-

178 Zur Entwicklung der Beziehungen zwischen den Sassaniden und Rom siehe Mi. Whitby 1988, 202-209; Blockley 1985 und Börm 2016; zu den römisch-persischen Kriegen der Spätantike siehe auch Greatrex/Lieu 2002 und zuletzt zum 6. und frühen 7. Jahrhundert Meier 2019a, 1020 - 1035.

179 Börm 2016, 624-633. Als Belisar im Jahr 530 bei Dara einen Sieg über die Perser errang, gelang es Justinian, den Triumph seines Generals im öffentlichen Raum Konstantinopels gänzlich auf sich zu übertragen: Auf dem Augusteion würdigte ein Reiterstandbild Justinian als Triumphator omnium gentium und auch im Hippodrom wurde er mit Widmungen als Sieger über Perser und Protobulgaren geehrt; siehe Börm 2013, 67. Allerdings muss hinzugefügt werden, dass 532 - also nur kurz nach dem Persertriumph - der Nika-Aufstand ausbrach, der Justinian beinahe zu Fall gebracht hätte; der Prestigegewinn durch den Persertriumph erwies sich also offenbar nicht als sonderlich nachhaltig.

180 Am ausführlichsten Joh. Eph. Hist. eccl. 3.2-5, der die Krankheit Justins als Strafe Gottes für dessen (miaphysitenfeindliche) Kirchenpolitik deutet. Zur Krönung des Tiberios zum Caesar durch Justin außerdem Evagr. Hist. eccl. 5.13, Theoph. Sim. Hist. 3.11.5-3.12.1.

181 Siehe etwa Av. Cameron 1976b.

$182 \mathrm{Zu}$ Justins Innenpolitik siehe Mi. Whitby 2000a, 87-90; zur Religionspolitik Av. Cameron 1976c. 183 Ähnlich bereits bei Börm 2013, 81f. Man könnte in diesem Zusammenhang gar noch weiter gehen und die These aufstellen, dass Tiberios die Erhebung des Justin 565 nicht nur mithilfe der ihm un- 
pation wählte Tiberios - folgt man dieser Deutung - einen wesentlich subtileren Weg der Ermächtigung. Mit dem ostentativen Einverständnis Justins übernahm er die Regierung, konnte sich als Caesar für die kaiserliche Nachfolge in Stellung bringen und nach seiner Krönung zum Augustus im palastinternen Machtkampf schließlich auch die Augusta Sophia und deren Parteiung ausstechen. ${ }^{184}$

Nach seiner Erhebung zum Caesar legte Tiberios den Fokus darauf, den östlichen Kriegsschauplatz wieder in den Griff zu bekommen, was ihm mit einer Mischung aus diplomatischer Annäherung und entschiedenem militärischem Vorgehen auch gelang. Im Jahr 575 oder 576 konnte er gar einen Triumph feiern: Nachdem einer persischen Armee die Überquerung des Euphrats missglückt war, fielen dem römischen Heer Kriegselefanten und weitere Beute in die Hände; die Feldherren schickten diese zum Caesar Tiberios nach Konstantinopel, wo die Spolien des römischen Erfolges der Bevölkerung präsentiert wurden. Der verantwortliche General Justinian - der jüngere Sohn des Germanos, Spross einer bedeutenden Militärdynastie ${ }^{185}$ - blieb im Osten, wo die Kämpfe andauerten. Tiberios musste sich in der öffentlichen Wahrnehmung also keines direkten Konkurrenten erwehren, sondern konnte den Sieg auf die eigene Person beziehen. ${ }^{186}$

Wenige Jahre später, 582, kehrte allerdings doch ein siegreicher General von der Perserfront nach Konstantinopel zurück: Maurikios, Tiberios' ehemaliger Comes excubitorum, der Justinian als Magister militum per Orientem ersetzt hatte. Theophanes berichtet, der Heimkehrer sei mit großen Ehren vom Kaiser empfangen worden; daraufhin habe „Tiberius einen Triumph für Maurikios’ Siege gefeiert“ und den General mit seiner Tochter Konstantina vermählt. ${ }^{187}$ Die Position des Triumphators und das Zentrum der Feierlichkeiten nahm also erneut, zumindest formal, der Kaiser ein; doch kam er offenbar nicht umhin, dem erfolgreichen General Zugeständnisse zu machen:

tergebenen Exkubitoren gedeckt hatte, sondern dass er maßgeblich für dessen Wahl verantwortlich gewesen war. Sich selbst bereits nach Justinians Tod für die Nachfolge in Stellung zu bringen, mag für Tiberios zu riskant gewesen sein, zumal mehrere hochrangige Verwandte Justinians zur Verfügung standen (neben Justin dem Curopalates auch Justin der General, Sohn des Germanos). Somit hätte Tiberios mit dem Zivilisten Justin den Kandidaten unterstützt, auf den er den größten Einfluss ausüben konnte. Diesen Gedanken verdanke ich Gesprächen mit Kai Trampedach.

184 Sophia (PLRE III, Aelia Sophia 1 [1179f.]) hatte offenbar eigene Ambitionen; sie soll es darauf abgesehen haben, Tiberios zu heiraten und damit ihre Position zu sichern; Tiberios war allerdings bereits mit Ino verheiratet und weigerte sich, sich scheiden $\mathrm{zu}$ lassen. Im Palast entbrannte ein Machtkampf, bis es Tiberios nach Justins Tod gelang, Sophia aus dem Palast zu entfernen, indem ihr vorgeworfen wurde, gemeinsam mit dem General Justinian, einem Cousin des Justin, gegen ihn intrigiert zu haben; zu Sophia und Tiberios siehe Garland 1999, 49-57 und Av. Cameron 1975.

185 PLRE IIIB, Iustinianus 3 (744-747); zu Justinian siehe oben S. 59.

186 Die genaue Ausgestaltung des Persertriumphes lässt sich nicht mehr rekonstruieren; welche Rolle Justin II. dabei einnahm, bleibt unklar; siehe McCormick 1986, 68f. (mit Angaben der Quellen), 129f.; Börm 2013, 83f.; Pfeilschifter 2016, 473.

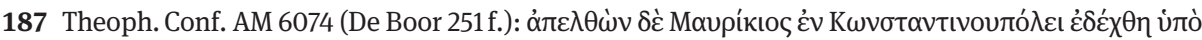

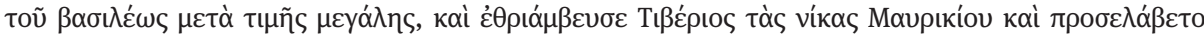

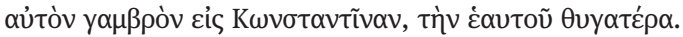


Der Vermählung mit Konstantina folgte Maurikios’ Erhebung in den Rang des Caesars. ${ }^{188}$ Zusammen mit Maurikios wurde allerdings noch ein weiterer Mann, nämlich Germanos, ${ }^{189}$ zum Caesar erhoben - eine Maßnahme, welche die Sukzessionsfrage zumindest zu einem gewissen Grade offen hielt und die interne Konkurrenz zwischen den beiden Anwärtern auf den Thron schürte. Der Persersieg und die ehrenvolle Rückkehr in die Hauptstadt, die nur kurze Zeit zurücklag, mögen schließlich dazu beigetragen haben, dass Maurikios sich wenige Tage später, angesichts Tiberius' kritischen Gesundheitszustandes, gegenüber dem Konkurrenten Germanos durchsetzen konnte: Er allein wurde zum Augustus gekrönt.

Die von Tiberius initiierten Vorstöße an der Perserfront gingen auf Kosten des Balkans, wo Avaren sowie slawische Stammesverbände die römischen Stellungen erneut unter Druck setzten. Als Tiberios 582 nach nur kurzer Regierung starb, waren die Fronten weder im Osten noch im Westen geklärt. ${ }^{190}$ Nachdem er die Alleinherrschaft angetreten hatte, führte Maurikios den Krieg über ein Jahrzehnt weiter. Als 589 oder 590 die Nachricht in Konstantinopel eintraf, dass die römische Armee unter der Führung des Herakleios (des Vaters des späteren Kaisers Herakleios) einen Sieg über die Perser errungen habe, veranlasste Maurikios Siegesfeierlichkeiten, die mit Pferderennen im Hippodrom begangen wurden. ${ }^{191}$ Auch diesmal verblieben die Generäle im Osten.

Eine entscheidende Wendung nahm der Konflikt zwischen Römern und Persern im darauffolgenden Jahr, als interne Machtkämpfe das persische Reich zu schwächen begannen. ${ }^{192}$ Der Großkönig Hormizdas, der nach dem Tod seines Vaters Chosroes I. im Jahr 579 an die Macht gekommen war, erwies sich innerhalb der persischen Elite als höchst umstritten; als Hormizdas' führender General Baram Chobin sich gegen ihn erhob und mit den Truppen auf Ctesiphon vorrückte, ${ }^{193}$ entluden sich die Spannungen: Hormizdas wurde abgesetzt und ermordet; an seiner Stelle rückte sein Sohn Chosroes II. als Großkönig nach. Baram Chobin gab sich mit diesem Arrangement allerdings nicht zufrieden und setzte Ctesiphon weiter militärisch unter Druck; Chosroes sah den einzigen Ausweg in der Flucht. Auf römischem Territorium angelangt bat er Maurikios mittels eines Sendschreibens um Hilfe gegen den Usurpator, der

188 Siehe dazu McCormick 1986, 69; Pfeilschifter 2016, 473.

$189 \mathrm{Zu}$ der Identität des Germanos siehe oben S. $59 \mathrm{f}$.

$190 \mathrm{Zu}$ der Außenpolitik des Tiberios siehe Jones 1964 I, 307-309; Mi. Whitby 1988, 258-275; Mi. Whitby 2000a, 95-98.

191 Theoph. Conf. AM 6080 (De Boor 262); Theoph. Sim. Hist. 3.6.5; McCormick 1986, 69 f.; Pfeilschifter 2016, 473.

192 Ein Überblick über die Ereignisse bieten Jones 1964 I, 310 f. und Mi. Whitby 2000, 103f., ausführlicher ders. 1988, 276-292.

193 Im Gegensatz zu seinem Vater führte Hormizdas seine Truppen nicht persönlich in den Krieg. Zwischen ihm und Baram Chobin, der gegen die Türken entscheidende Siege hatte einfahren können, entspann sich ein Wettstreit. Nachdem Hormizdas Baram Chobin öffentlich gedemütigt hatte, kam es zur Rebellion; zu Baram Chobin und den unterschiedlichen Überlieferungssträngen hinsichtlich des Ausbruchs der Revolte siehe Bonner 2020, 247-251. 
sich inzwischen zum Großkönig hatte krönen lassen. ${ }^{194}$ Maurikios willigte ein, den Erben der sassanidischen Dynastie zu unterstützen.

Die letzten Jahrzehnte hatten deutlich gezeigt, dass aggressives Vorgehen gegenüber dem persischen Reich hohe Risiken barg und Konstantinopel in der Regel geschwächt aus der Konfrontation hervorging. Warum fällte Maurikios dennoch die Entscheidung, aktiv in die persischen Thronwirren einzugreifen und sich damit noch weiter in den seit Jahrzehnten schwelenden Konflikt zu verstricken? Michael Whitby sieht Maurikios' Entscheidung von der Hoffnung getrieben, durch die Unterstützung des dynastisch legitimierten Herrschers die Ostgrenze endgültig zu befrieden und erneut ein stabiles Verhältnis zum Nachbarn zu erwirken. ${ }^{195}$ Darüber hinaus scheint allerdings noch ein weiterer Faktor das römische Engagement bedingt zu haben: nämlich das spezielle Verhältnis der beiden Großmächte zueinander mit dem Potential, Parallelen in ihren jeweiligen Herrschaftsstrukturen auszumachen. ${ }^{196}$ Maurikios konnte den Sturz des persischen Großkönigs durch seinen höchsten General nicht hinnehmen, da der persische Coup als Präzedenzfall für mögliche Entwicklungen im römischen Reich hätte dienen können; denn in der Überwältigung des Souveräns durch hohe Militärs lag eben die Gefahr, der sich auch die römischen Kaiser stets erwehren mussten.

Maurikios war sich offenbar des Risikos bewusst, das eine Eskalation des Perserkrieges nicht nur für den Zustand des römischen Heeres, sondern auch hinsichtlich der innenpolitischen Stabilität mit sich bringen konnte. Die Logik seines Handelns erschließt sich beim Blick auf die Chronologie. Nachdem das persische Heer zum Usurpator Baram Chobin übergelaufen waren, floh Chosroes am 1. März 590 auf römisches Territorium. Vom Statthalter Probos in Circensium in Empfang genommen, veranlasste er das oben erwähnte Schreiben an Maurikios. Über Hierapolis gelangte die Depesche nach Konstantinopel. ${ }^{197}$ Maurikios seinerseits erhob am 26. März, an

194 Zum persischen Bürgerkrieg vgl. Mi. Whitby 1988, 292-297 und Bonner 2020, 253-263; außerdem Rubin 2004.

195 Mi. Whitby 1988, 299. Ob Chosroes nach seiner Flucht gegenüber den Römern tatsächlich den Eindruck erweckte, zum Christentum konvertieren $\mathrm{zu}$ wollen, wie es manche Quellen suggerieren (Theoph. Sim. Hist. 4.6.1-3 und Evagr. Hist. eccl. 6.17), und damit die Hoffnung schürte, nach einer Wiedereinsetzung ganz Persien für den christlichen Glauben zu gewinnen, ist fraglich.

196 Gemeinsamkeiten und Unterschiede auf herrschaftsstruktureller Ebene trägt Börm 2010 zusammen. In dem bei Theophylakt Simokattes überlieferten Brief (Hist. 4.11.1-11), mit dem Chosroes II. sich nach seiner Flucht an Maurikios wandte, wird nicht nur die Erhabenheit, sondern auch die Gleichrangigkeit der beiden Nachbarn als „zwei Augen der Erde“ betont (dieses Bild findet sich bereits in Petr. Patric. fragm. 13). Whitby/Whitby 1986, 113, 25 halten den Brief für eine authentische Übersetzung

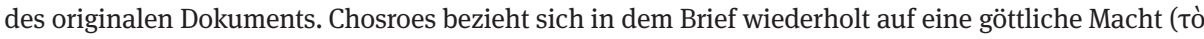
$\theta \varepsilon \tilde{o v}$ ); man könnte sich vorstellen, dass die Formulierung auch im Original bewusst offengehalten wurde, um auch einen christlichen Gott einzuschließen.

197 Theoph. Sim. Hist. 4.9.10.-4.10.10 mit den Kommentaren zu den Daten von Whitby/Whitby 1986, 115-117; zu Chosroes’ Flucht außerdem Bonner 2020, 259-261. 
Ostern, seinen ältesten Sohn, den siebenjährigen Theodosios, zum Augustus. ${ }^{198}$ Dass der Kaiser sich ausgerechnet in diesem Moment - also kurz nachdem die Depesche in der Hauptstadt eingetroffen sein muss ${ }^{199}$ - zur Designation eines Nachfolgers entschloss, kann kaum ein Zufall sein. Von dem Coup in Persien und dem Hilfegesuch Chosroes', welches er schwerlich abschlagen konnte, in Kenntnis gesetzt, sah sich Maurikios zu schnellem Handeln gedrängt. ${ }^{200}$ Er selbst war ein knappes Jahrzehnt zuvor als Persersieger von Tiberius zum Caesar erhoben worden; der Wiederholung eines derartigen Szenarios galt es nun, da der Konflikt eine entscheidende Wendung zu nehmen versprach, vorzubeugen. Mit der Krönung seines Sohnes zum Augustus gedachte Maurikios offenbar, die Nachfolgefrage zu klären, bevor weitere Schritte in Bezug auf die Situation in Persien eingeleitet wurden. ${ }^{201}$

Unter massiven militärischen Anstrengungen konnte der Usurpator Baram Chobin besiegt und Chosroes wiedereingesetzt werden. Maurikios' Risikobereitschaft zahlte sich aus: Der römische Einsatz brachte die Rückgabe von Dara und Martyropolis sowie die Übernahme von Iberien und eines großen Teiles Persarmeniens. Der von Justin II. überstürzt vom Zaun gebrochene Krieg, der über zwei Jahrzehnte an den römischen Ressourcen gezehrt hatte, konnte 591 gar mit einem Gebietsgewinn zu Ende gebracht werden. ${ }^{202}$ Über den prestigeträchtigen Persersieg hinaus hatte Maurikios' Engagement zu einer Propagatio imperii geführt, wie sie seit Langem keinem römischen Kaiser mehr beschert gewesen war: Ein Erfolg, so sollte man meinen, von enormer Öffentlichkeitswirkung. Spuren von triumphalen Feierlichkeiten in der Hauptstadt, die den Erfolg gegen Baram Chobin und den Zugewinn an römischem Territorium zelebrierten, sucht man in den Quellen allerdings vergeblich; dieser Befund verwundert. ${ }^{203}$ Warum machte der Kaiser den bemerkenswerten Erfolg über die Perser nicht im hauptstädtischen Kontext für sich nutzbar, wie es seine Vorgänger Tiberios oder Justinian, teilweise bei wesentlich weniger substanziellen Anlässen, getan hatten? Angesichts der sporadischen Quellenlage können als Antwort auf diese

198 Chron. Pasch. AD 590; Theoph. Conf. AM 6082 (De Boor 267); zu Theodosios siehe PLRE IIIB, Theodosius 13 (1293f.).

199 Angesichts der höchsten Priorität, die der Angelegenheit sicherlich von allen Beteiligten zuerkannt wurde, ist davon auszugehen, dass die Depesche die Hauptstadt verhältnismäßig rasch erreichte.

200 Die Korrelation von Chosroes Hilfegesuch und Theodosios' Krönung, mehr noch die kausale Bedingtheit, wird weder in den Quellen angezeigt, noch wurde sie bisher von der Forschung gesehen. Dass Kaiser ihre Söhne gerade in politisch prekären Zeiten zu Caesaren oder Augusti erhoben, ist allerdings naheliegend; so geschehen auch im Falle des Honorius, den sein Vater Theodosios I. im Jahr 393 in Reaktion auf die Usurpation des Eugenius zum Augustus erhob.

201 Chron. Pasch. AD 590 hält fest, dass Theodosios zwar von Maurikios gekrönt, aber nicht von der Öffentlichkeit akklamiert oder in die offiziellen Register aufgenommen wurde.

202 Vgl. Mi. Whitby 1988, 297-304.

203 Die ausführlichste Quelle zur Regierung des Maurikios sind die Historien des Theophylakt Simokattes, die - verschriftlicht unter der Herakleios - darum bemüht waren, Maurikios' Andenken zu rehabilitieren. Dass ausgerechnet diese Quelle einen von Maurikios gefeierten Perser-Triumph, hätte er denn stattgefunden, überging, ist äußerst unwahrscheinlich; siehe dazu Börm 2013, $84 \mathrm{f}$. 
Frage nur Spekulationen angeführt werden. Wollte Maurikios vor dem hauptstädtischen Publikum eine für ihn potentiell kritische Hervorhebung des Generals Narses vermeiden, der als Magister militum den Sieg über Barams Truppen verantwortet hatte?204

An dieser Stelle bietet es sich an, Maurikios’ Verhältnis zum militärischen Sektor sowie seine Initiativen im militärischen Bereich genauer in den Blick zu nehmen. Dabei fällt zunächst auf, dass Maurikios in noch höherem Maße als seine Vorgänger versucht zu haben scheint, persönlich in die Dynamiken des militärischen Sektors in den Provinzen einzugreifen. Formen der Ermächtigung gegenüber hohen militärischen Funktionsträgern, derer sich bereits seine Vorgänger bedient hatten, fanden gehäuft Anwendung: Als Kaiser, der darauf bedacht war, eine neue Dynastie zu etablieren, fokussierte sich Maurikios auf die Förderung der eigene Familie, deren Mitglieder durch verschiedene Formen der Zuwendung, unter anderem auch finanzieller Art, konsequent aufgebaut und in bedeutenden Ämtern installiert wurden. ${ }^{205}$ Innerhalb dieses Kreises kam es nicht nur zu einer Vermischung ziviler und militärischer Kompetenzen; ${ }^{206}$ auch die Praxis, Befehlshabern der Palastgarden gleichsam Kommandos über Provinzheere zu übertragen und damit das kaiserliche Kontrollspektrum auszuweiten, wurde von Maurikios weitergeführt. ${ }^{207}$

Im Gegensatz zu seinen Vorgängern ging Maurikios allerdings über die Entsendung enger Vertrauter in die Provinzen hinaus. Nachdem sich die Kaiser über beinahe zwei Jahrhunderte im städtischen Palastumfeld eingerichtet hatten, machte Maurikios erstmals seit Theodosios I. wieder konkrete Anstalten, persönlich als Heerführer aktiv zu werden. Angesichts von Vorstößen der Avaren leitete Maurikios mehrmals die Befestigung der Langen Mauern, des ca. 64 km westlich vor Konstantinopel gelegenen Verteidigungswalls, der die gesamte thrakische Halbinsel durchspannte. ${ }^{208}$ Maurikios’

204 Da der Krieg im Osten mit dem römischen Sieg vorerst beendet war, konnte Maurikios den Feldherren nicht schlichtweg in der Provinz ausharren lassen. Es bleibt jedoch unklar, warum Maurikios nicht eine Lösung hätte wählen können, die dem Vandalentriumph von 534 entsprach, bei dem der siegreiche Feldherr Belisar zum Zuge kam, sich aber gleichzeitig unter Justinian als eigentlichen Triumphator unterordnete.

205 Mi. Whitby 1988, 14-17 und ders., 2000a, 100: Maurikios’ Vater Paulos stieg zum Caput senatus auf; sein Cousin bzw. Neffe Domitian wurde als Bischof von Melitene installiert, reiste allerdings auch als Gesandter zum persischen Großkönig Hormizdas.

206 Maurikios' Bruder Petros (PLRE IIIB, Petrus 55 [1009-1011]) wurde zum Curopalates ernannt und außerdem als General auf dem Balkan eingesetzt.

207 Philippikos (PLRE IIIB, Philippicus 3 [1022-1026]), der Ehemann seiner Schwester Gordia, besetzte sowohl das Amt des Comes excubitorum als auch des Magister militum per Orientem.

208 Bereits 584 unternahm Maurikios nach einem Einfall der Avaren eine Expedition zu den Langen Mauern, begleitet von seiner Garde und laut Theophanes auch von den Demen (Theoph. Sim. Hist. 1.7.2 und Theoph. Conf. AM 6076 [De Boor 254]); 598 befestigte Maurikios gemeinsam mit Heer, den Exkubitoren und Vertretern der Zirkusparteien erneut die Langen Mauern (Theoph. Sim. Hist. 7.15.7 und dazu Mi. Whitby 1988, 163). Eine Begehung der Langen Mauern - anlässlich von Reparaturarbeiten nach Erdbebenschäden - hatte bereits Justinian einige Jahrzehnte zuvor unternommen; seine Rückkehr in die Stadt war damals von groß angelegten, vor allem religiös konnotierten Feierlichkeiten 
Engagement beschränkte sich jedoch nicht allein auf die akute Sicherung der Hauptstadt: Eine mehrwöchige Expedition durch Thrakien führte ihn an der Spitze der römischen Truppen bis nach Anchialos an der Schwarzmeerküste, wo er die Schäden der avarischen Plünderungen begutachtete. Aufgrund von Unstimmigkeiten in den Quellen bleibt die genaue Datierung dieser Expedition, von der Theophylakt Simokattes am ausführlichsten berichtet, umstritten. ${ }^{209}$ Dass Maurikios sich persönlich in Thrakien betätigte, während die Situation in Persien noch unentschieden war, ist indes eher unwahrscheinlich; es erscheint plausibler, dass der Kaiser die Expedition nach der erfolgreichen Beilegung des Perserkrieges 591 mit den aus dem Osten abgezogenen Truppen durchführte - nicht zuletzt, um die schlagkräftigsten Einheiten des römischen Heeres wieder stärker an seine Person zu binden. ${ }^{210}$ Bemerkenswert ist in diesem Zusammenhang, dass Maurikios' Vorhaben - unabhängig von der Datierungsfrage - einen Einblick in die Stimmungslage des hauptstädtischen Palastumfeldes gibt, dessen Protagonisten mit deutlicher Ablehnung auf das kaiserliche Engagement am Kriegsschauplatz reagierten. Indem der Kaiser an der Spitze der römischen Truppen gen Westen aufbrach, setzte er sich über den Appell der Senatoren, des Patriarchen sowie seiner Familie hinweg, einen General zu bestellen, anstatt selbst ins Feld zu ziehen. ${ }^{211}$

Maurikios versuchte offenbar, im Umgang mit dem militärischen Sektor eigene Impulse zu setzen. Der Umstand, dass er vor seiner Designation durch Tiberios umfassende Erfahrung als Feldherr hatte sammeln können, mag der umstrittenen Entscheidung, persönlich nach Thrakien aufzubrechen, zuträglich gewesen sein; dabei bleibt allerdings erneut zu betonen, dass auch diejenigen seiner Vorgänger, die einen militärischen Karrierepfad begangen hatten, nach ihrer Krönung stets in Konstantinopel geblieben waren. Die hier gewählte Perspektive legt die Interpretation nahe, dass hinter Maurikios' Bruch mit kaiserlicher Verhaltenspraxis der Versuch stand, die Autonomie der in den Provinzen operierenden Generäle durch persönliche Präsenz einzuschränken und den militärischen Sektor enger an die Autorität des Monarchen zu binden. Doch Maurikios' Versuche, seinen Handlungsspielraum zu erweitern, wurden im Keim erstickt: Ohne einem einzigen Feind begegnet zu sein, brach er die

begleitet worden (Theoph. Conf. AM 6051 [De Boor 234] und De cerim. 1 App. [Reiske 497f.]); siehe McCormick 1986, 67; Leppin 2011, $321 \mathrm{f}$.

209 Theoph. Sim. Hist. 5.16-6.3.8; Theoph. Conf. AM 6083 (De Boor 268f.): Theophylakt setzt seinen Bericht über die Expedition nach Anchilaos nach der Beilegung des Perserkrieges 591 an, scheint dabei allerdings Elemente von unterschiedlichen Aufenthalten des Maurikios in Thrakien zusammenzuwerfen: einen Aufenthalt, der mit Verweis auf eine Sonnenfinsternis auf den Oktober 590 datiert werden kann, und einen, der mit der Ankunft einer Gesandtschaft des fränkischen Königs Theoderich in Verbindung steht - Theoderich wurde erst Weihnachten 595 gekrönt; zu den Problemen mit der Chronologie siehe die Kommentare bei Whitby/Whitby 1986, 155 Anm. 86, 200 Anm. 73 und Mango/ Scott 1997, 392 Anm. 1, 405 Anm. 12; außerdem Mi. Whitby 1988, 156-158.

210 Theoph. Sim. Hist. 5.16.1 legt den Zusammenhang zwischen der Verlagerung des Heeres und der kaiserlichen Expedition nahe.

211 Theoph. Sim. Hist. 5.16.2-4. 
Thrakien-Expedition nach wenigen Wochen ab und kehrte in die Hauptstadt zurück. Der konkrete Anlass für seine Rückkehr war laut Theophylakt Simokattes die Ankunft mehrerer Gesandtschaften in Konstantinopel - einer persischen Delegation sowie einer Gesandtschaft des frisch gekrönten fränkischen Königs Theoderich -, derer sich der Kaiser persönlich annahm. ${ }^{212}$

Maurikios' Thrakien-Expedition wirft ein Schlaglicht auf das Dilemma des regierenden Kaisers. Die Strukturen, die sich über zwei Jahrhunderte hauptstädtischer Monarchie herausgebildet hatten, fesselten den Kaiser geradezu an Konstantinopel als zentraler Aushandlungsort monarchischer Herrschaft und schränkten seine Bewegungsfreiheit massiv ein; wie aus dem Bericht des Theophylakt hervorgeht, drängten die hauptstädtischen Interessensgruppen auf Kaisernähe. Die zentrale Herausforderung für den Kaiser war es, einerseits den Verhaltenserwartungen der hauptstädtischen Gruppen gerecht zu werden und deren Akzeptanz zu sichern, und andererseits seine Autorität über den militärischen Sektor soweit es ging zu wahren vor allem in Zeiten erhöhter militärische Aktivität. Es war äußerst riskant, die unmittelbare Kontrolle über Konstantinopel durch längere Abwesenheit zu gefährden; ein derartiges Machtvakuum hätte allzu leicht durch einen potentiellen Herausforderer ausgenutzt werden können. Um seine Rolle als Gravitationspunkt palatialer Machtstrukturen auszufüllen, begab sich Maurikios zurück nach Konstantinopel, als die Ankunft der Gesandtschaften repräsentative Anlässe erforderten.

Der kursorische Blick auf die Regierung des Maurikios legt nahe, dass der Kaiser sich wiederholt Interaktionsmöglichkeiten mit den herrschaftsrelevanten Gruppen Konstantinopels entgehen ließ, die seine Herrschaft hätten stabilisieren können. Er war offenbar nicht in der Lage, den römischen Triumph über die Perser im hauptstädtischen Umfeld durch typische Formen der triumphalen Repräsentation nutzbar zu machen. Wenn auch nicht direkt schädlich fürs kaiserliche Prestige, so kann dies zumindest als verpasste Chance gewertet werden. Seinen ältesten Sohn Theodosios erhob er 590 zwar zum Augustus, ließ ihn allerdings nicht - wie die Osterchronik explizit festhält - in der Öffentlichkeit akklamieren; ${ }^{213}$ ein derartiger Akt hätte die Bevölkerung noch enger an die Kaiserfamilie binden können. Maurikios war sich offenbar durchaus der Risiken bewusst, die vom militärischen Sektor ausgehen konnten; seine halbherzige Thrakien-Expedition scheint allerdings nicht die erhofften Effekte gezeitigt zu haben. Es sticht ins Auge, dass der Kaiser im Zusammenhang mit militärischen Angelegenheiten trotz seiner Erfahrung als Feldherr wiederholt Entscheidungen traf, die letztendlich seine Position negativ beeinträchtigen. Dies äußert sich besonders deutlich darin, dass sich unter Maurikios' Regierung wiederholt Widerstand aus den Reihen des Heeres regte. Die Konflikte zwischen dem Kaiser und den

212 Theoph. Sim. Hist. 6.3.5-8.

213 Chron. Pasch. AD 590. Einen gänzlich anderen Weg ging Herakleios ca. zwanzig Jahre später, als er die Krönung seines Sohnes Herakleios Konstantin im Jahr 613 auf verschiedenen Kanälen gegenüber der Öffentlichkeit kundtat; dazu gehört auch, dass Herakleios Konstantin auf allen Münznominalen neben seinem Vater erschien; siehe unten Kap. 4.3; 4.3.1. 
Soldaten, welche bisweilen in längerfristigen Befehlsverweigerungen eskalierten, entzündeten sich allesamt in Situationen, in denen Provinzheere ihre Interessen nicht angemessen vertreten sahen, etwa angesichts der Bestellung unbeliebter Befehlshaber oder Soldkürzungen. Maurikios verscherzte es sich konsequent mit der Gruppe, die in der Regel - wie oben besprochen - auf den sesshaften Kaiser bezogen blieb, solange ihre Bedürfnisse gedeckt blieben. Das Gros der Forschung sieht hinter diesen Maßnahmen nicht etwa Maurikios’ Fahrlässigkeit bei der Administration, sondern vielmehr sein Bemühen darum, die angeschlagenen Staatskassen zu schonen; schon zu Lebzeiten haftete dem Kaiser der Ruf des Geizhalses an. Doch wie sich im nächsten Kapitel zeigen wird, sollte seine Beharrlichkeit und Kompromisslosigkeit gegenüber den Belangen der Soldaten eine Dynamik in Gang setzen, die letztendlich in seinem Sturz kulminierte. 